UNIVERSIDADE DE SÃO PAULO

ESCOLA DE EDUCAÇÃO FÍSICA E ESPORTE

\title{
AVALIAÇÃO ERGONÔMICA DO MEMBRO \\ SUPERIOR ESQUERDO DE OPERADORES DE TREM \\ METROPOLITANO: UMA INVESTIGAÇÃO DE SOBRECARGAS NO SISTEMA OSTEOMUSCULAR
}

Wilson Viana de Castro Melo

SÃO PAULO

2007 


\section{AVALIAÇÃO ERGONÔMICA DO MEMBRO \\ SUPERIOR ESQUERDO DE OPERADORES DE TREM METROPOLITANO: UMA INVESTIGAÇÃO DE SOBRECARGAS NO SISTEMA OSTEOMUSCULAR}

Wilson Viana de Castro Melo

Dissertação apresentada à Escola de Educação Física e Esporte da Universidade de São Paulo, como requisito parcial para obtenção do grau de Mestre em Educação Física, 
Melo, Wilson Viana de Castro

Avaliação ergonômica do membro superior esquerdo de operadores de trem metropolitano: Uma investigação de sobrecargas no sistema osteomuscular / Wilson Viana de Castro Melo. - São Paulo : [s.n.], 2008. xi, 72p.

Dissertação (Mestrado) - Escola de Educação Física e Esporte da Universidade de São Paulo.

Orientador: Prof. Dr. Marcos Duarte.

1. Biomecânica I. Título. 


\section{AGRADECIMENTOS}

Primeiramente agradeço a esta força poderosa que mim impulsiona a continuar nesta caminhada. Obrigado meu Deus, pela possibilidade desta realização.

Agradeço a minha família: pais, irmãos, esposa e filhos, pela confiança e paciência depositados na minha pessoa.

A Escola Superior de Educação Física da Universidade de Pernambuco pela oportunidade e colaboração na realização deste trabalho.

A todas da Companhia Brasileira de Trens Urbanos que confiaram neste trabalho, em especial ao Sr. João Dias, presidente da CBTU.

Ao meu amigo José Innocêncio pelo apoio e ajuda nesta tarefa.

A minha grande amiga Terezza Cattuzzo por proporcionar-me esta realização profissional.

Ao meu amigo Hilton Coutinho pela paciência, compreensão e acolhida.

Ao meu orientador Prof. Dr. Marcos Duarte pela paciência, amizade e confiança.

A todos os professores que participaram desta minha nova formação acadêmica.

A todos os colegas do LOB e LACOM, pelos bons momentos compartilhados.

A todos os funcionários da Escola de Educação Física e Esporte da Universidade de São Paulo que colaboraram para a realização deste estudo.

A CAPES por financiar este programa de qualificação.

$\mathrm{E}$ a todos que direta ou indiretamente colaboraram para a realização desta conquista. 
SUMÁRIO

Página

LISTA DE TABELAS

$-\mathrm{V}$

LISTA DE FIGURAS -

LISTA DE ANEXOS -- vii

RESUMO----

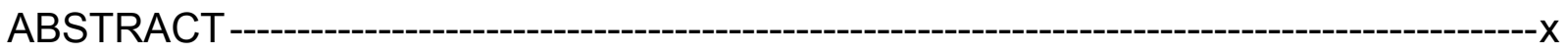

1 INTRODUÇÃO --

1.2 Justificativa --a-12

1.3 Questão----

2 OBJETIVO-- 13

2.1 Objetivos específicos ---_-

3 REVISÃO DA LITERATURA --13

3.1 A relação homem - trabalho --

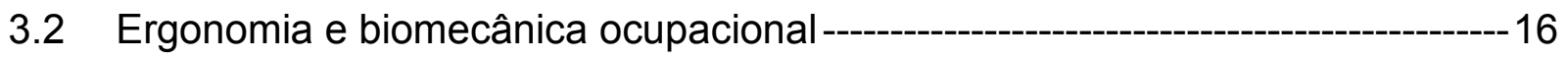

3.3 O membro superior -

3.4 Distúrbios osteomusculares relacionados ao trabalho---_-_-_-_-_-_-_-_-_-_---19

3.4.1 Terminologia e conceitos----_o

3.4.2 Breve histórico -----_-

3.4.3 Etiologia--

3.5 Método RULA --- 25

3.6 Dinâmica inversa-

3.7 Eletromiografia--

4 MATERIAL E MÉTODOS --30

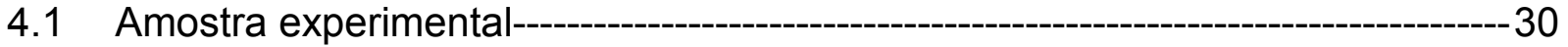

4.2 Procedimentos ---

4.3 Tarefa --o-31

4.4 Instrumentos -

4.4.1 Questionário Nórdico de Sintomas Osteomusculares - QNSO-_-_-_-_-33

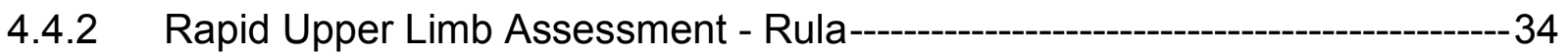

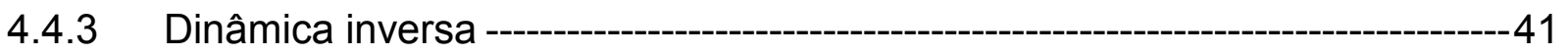




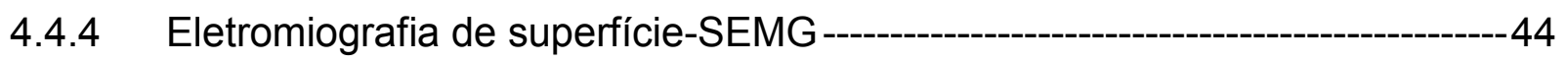

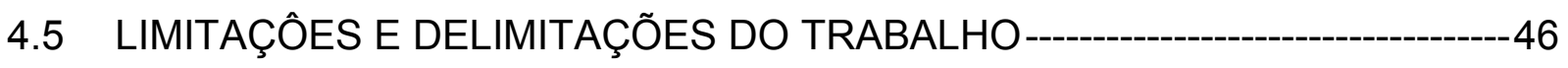

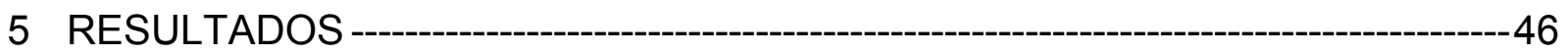

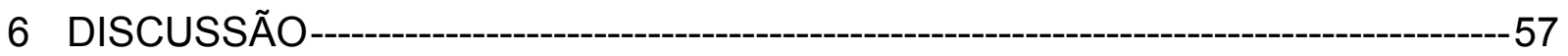

6.1 Escore da atividade -

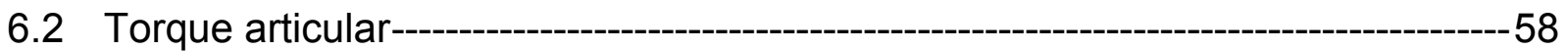

6.3 Freqüência mediana ----10

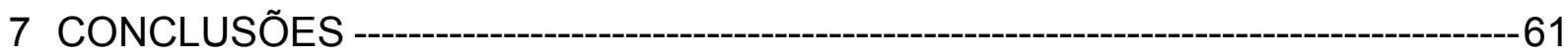

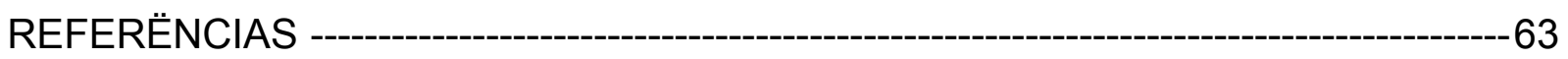

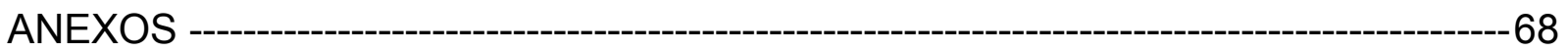




\section{LISTA DE TABELAS}

Página

TABELA 1 - Combinações das posturas individuais das articulações dos membros superiores para determinação do escore $A$

TABELA 2 - Combinações das posturas individuais das articulações dos membros inferiores para determinação do escore $B$

TABELA 3 - Cruzamento dos escores parciais C e D para determinação do escore final

TABELA 4 - Prevalência do sintoma de dor desconforto ou dormência por regiões do corpo nos últimos 12 meses.

TABELA 5 - Escores finais da atividade para cada maquinista com percentual do tempo de permanência na postura estática referente ao ponto de tração zero

TABELA 6 - Valores dos torques no ombro para cada ponto do manete de tração em $\mathrm{Nm}$

TABELA 7 - Freqüências medianas do músculo Tríceps Braquial

TABELA 8 - Freqüências medianas dos músculos flexores do punho

TABELA 9 - Valores máximos do RMS normalizado pela CVMI para o músculo Tríceps Braquial

TABELA 10 - Valores máximos do RMS normalizado pela CVMI para os músculos flexores do punho 


\section{LISTA DE FIGURAS}

Página

FIGURA 1 - Modelo do sistema homem-tarefa 15

FIGURA 2 - Diagrama das alterações espectrais que ocorrem com o sinal EMG durante contrações sustentadas. Adaptado de DE LUCA (1997) .........29

FIGURA 3 - Postura do maquinista durante o trabalho 32

FIGURA 4 - Manete de tração. 33

FIGURA 5 - Escores de classificação das posturas do corpo pertencentes ao grupo A 35

FIGURA 6 - Escores de classificação das posturas do corpo pertencentes ao grupo B

FIGURA 7 - Esquema de inserção dos escores para determinação do escore final..40

FIGURA 8 - Marcadores refletivos e respectivos pontos anatômicos 41

FIGURA 9 - Célula de carga fixada à manete de tração 42

FIGURA 10 - Diagrama de Corpo Livre do membro superior - Plano Sagital..... .43

FIGURA 11 - Determinação dos pontos motores 44

FIGURA 12 - Valores médios dos torques aplicados sobre a articulação do ombro..50 FIGURA 13 - Espectros de potência do sinal eletromiográfico do músculo Tríceps Braquial.

FIGURA 14 - Boxplot das freqüências medianas do músculo tríceps braquial 53

FIGURA 15 - Boxplot das freqüências medianas dos músculos flexores do punho..54 FIGURA 16 - Representação gráfica do RMS para os músculos Tríceps Braquial e flexeros do punho normalizado pela CVMI 


\section{LISTA DE ANEXOS}

Página

ANEXO I - Valores das medidas antropométricas para o peso corporal, envergadura, comprimento do braço, antebraço e mão ..............................................68

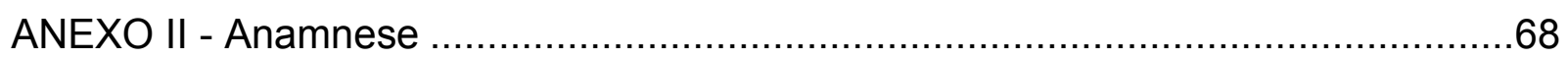

ANEXO III - Questionário Nórdico de Sintomas Osteomusculares - QNSO ..............70 


\title{
AVALIAÇÃO ERGONÔMICA DO MEMBRO SUPERIOR ESQUERDO DE OPERADORES DE TREM METROPOLITANO: UMA INVESTIGAÇÃO DE SOBRECARGAS NO SISTEMA OSTEOMUSCULAR
}

\author{
Autor: WILSON VIANA DE CASTRO MELO \\ Orientador: Prof. DR. MARCOS DUARTE
}

\begin{abstract}
A Biomecânica Ocupacional procura aprimorar as condições de trabalho objetivando prevenir e reduzir as lesões, aumentar o desempenho dos operários reduzindo sobrecargas. Pesquisas nesta área indicam que não apenas a manipulação de materiais pesados, mas também posturas pouco naturais e movimentos súbitos e inesperados provocam lesões no sistema osteomuscular que afetam principalmente o pescoço, membros superiores e região lombar. Alguns profissionais apresentam alto risco ao aparecimento desses distúrbios envolvendo principalmente os membros superiores e região lombar, particularmente os digitadores, operadores de caixa de supermercados, dentistas, motoristas profissionais e operadores de trens metropolitanos. Este estudo teve como objetivo estimar a carga mecânica e a atividade muscular no membro superior esquerdo de maquinistas condutores de trens metropolitanos durante o trabalho. Especificamente, o estudo procurou estimar a carga mecânica sobre a articulação do ombro, avaliar a atividade muscular dos músculos tríceps e flexores do punho e verificar a ocorrência de fadiga muscular durante a realização da tarefa, para isto foram investigados o fator de risco relacionado a enfermidades dos membros superiores, o torque sobre a
\end{abstract}


articulação do ombro e a freqüência mediana do sinal eletromiográfico. O método RULA indicou para atividade estudada um escore final quatro, que sugere mais investigações e mudanças podem ser requeridas, pois a postura adotada gera desconforto. O torque calculado sobre a articulação do ombro é aplicado por cerca da metade da jornada de trabalho e apresentou valor médio de $-4,1 \mathrm{Nm}$ com o manete na posição 0. A instauração de fadiga sobre os músculos Tríceps Braquial e flexores do punho não foi observada. Estudos futuros são recomendados para desenvolvimento de cabinas de trens metropolitanos com layout ergonômico e posicionamento de instrumentos que possibilite uma postura mais adequada dos operadores.

Palavras Chaves: Biomecânica Ocupacional, sistema osteomuscular, trem metropolitano, RULA, torque, freqüência mediana, fadiga. 


\title{
ERGONOMIC EVALUATION OF THE LEFT UPPER LIMB OF METROPOLITAN TRAIN DRIVERS: AN INVESTIGATION OF OVERLOADS IN THE MUSCULOSKELETAL SYSTEM
}

\author{
Author: WILSON VIANA DE CASTRO MELO \\ Adviser : Prof. DR. MARCOS DUARTE
}

Occupational biomechanics seeks to improve the conditions of work aiming to prevent and to reduce the injuries, to increase the performance of workers reducing overloads. Previous researches in this area indicate that not only handling the of heavy material, inadequate postures and unexpected and sudden movements provoke injuries in the musculoskeletal system that affect mainly the neck, upper limbs and the lumbar region. Some workers present high risk to the develop those disturbances involving mainly the upper limbs and the lumbar region, particularly the keyboarders, supermarket cashiers, dentists, professional drivers and operators metropolitan train. This study aimed to estimate the mechanical load and the muscular activity in the left upper limb of metropolitan train drivers during the work. Specifically, the study sought to estimate the mechanical load on the joint of the shoulder, evaluate the muscular activity of the muscles triceps and flexors of the wrist and verify the occurrence of muscular fatigue during the achievement of the task. For this purpose, it were investigated the risk factor related to the diseases of the upper limbs, the torque on the joint of the shoulder and the median frequency of the electromyographic signal. The method RULA indicated for activity a score final four, which suggests more investigations and changes may be required because the usual posture adopted generates discomfort. The calculated torque on the joint of the shoulder is applied by about half of the day at work and showed the average value of 
$-4.1 \mathrm{Nm}$ with the handle in position 0 . The instauration of fatigue on the muscles Tríceps brachial the wrist flexor was not observed. Thus, future studies are recommended to the development of the metropolitan trains' berths with ergonomic layout and positioning of instruments that enables an adequate posture of its users.

Keywords: Occupational biomechanics, musculoskeletal system, metropolitan train, Rula, torque, average frequency, fatigue. 


\section{INTRODUÇÃO}

Toda atividade laboral é concluída através do empenho das pessoas. A Biomecânica Ocupacional procura aprimorar as condições de trabalho objetivando prevenir e reduzir as lesões, como também aumentar o desempenho dos operários, reduzindo sobrecargas, a fim de evitar patologias como os Distúrbios Osteomusculares Relacionados ao Trabalho (DORT) ou Lesões por Esforços Repetitivos (LER) (CHAFFIN, ANDERSSON \& MARTIN, 1997).

Pesquisas nesta área indicam que não apenas a manipulação de materiais pesados, mas também posturas pouco naturais e movimentos súbitos e inesperados provocam lesões no sistema osteomuscular que afetam principalmente o pescoço, membros superiores e região lombar (NIOSH, 1997)

Uma larga variedade de enfermidades humanas e limitações do desempenho têm sido evidenciadas sob a responsabilidade de soluções biomecânicas (CHAFFIN, ANDERSSON \& MARTIN, 1997).

A Organização Mundial de Saúde (OMS) caracteriza doenças relacionadas ao trabalho como sendo multifatoriais, ou seja, não apenas um, mas vários fatores contribuem para o aparecimento dessas doenças (NIOSH, 1997). Tais fatores foram estabelecidos na maior parte dos casos, por meio de observações empíricas e confirmadas posteriormente com estudos epidemiológicos (MPAS, 2003).

Alguns profissionais apresentam alto risco ao aparecimento de DORT envolvendo principalmente os membros superiores e região lombar, populações particularmente afetadas são os digitadores, operadores de caixa de supermercados, dentistas, motoristas profissionais (MASSACCESI, PAGNOTTA, SOCCETTI, MASALI, MASIERO \& GRECO, 2003) e operadores de trens metropolitanos ( AUSTIN \& DRUMMOND, 1986; SEN \& GANGULI, 1982; STEVENSON, COLEMAN, LONG \& WILLIAMSON, 2000).

\section{$1.1 \quad$ Justificativa}

A atividade de condução do Trem Metropolitano da Cidade do Recife executada pelos maquinistas, sempre foi, ao longo desse vários anos de minha 
experiência e convivência de trabalho com esta população, motivo de diversas críticas e queixas de dores musculares no punho e ombro, pois os maquinistas devem manter o manete de tração (dispositivo responsável pela aceleração do trem) constantemente pressionado para baixo.

Diante do fato, pretendeu-se investigar os esforços impostos ao membro superior esquerdo dos maquinistas, durante uma jornada de trabalho, a fim de identificar se estas cargas são responsáveis pelas citadas queixas de dores musculares no membro superior esquerdo, sendo um fator de risco para o aparecimento de distúrbios osteomusculares.

\section{Questão}

A carga mecânica e a fadiga imposta ao membro superior esquerdo durante a condução do Trem Unidade Elétrica (TUE) possibilitam o aparecimento de distúrbios osteomusculares?

2

\section{OBJETIVO}

Estimar a carga mecânica e a fadiga muscular no membro superior esquerdo em maquinistas condutores de trens metropolitanos, durante o trabalho.

\section{$2.1 \quad$ Objetivos específicos}

1. Determinar o fator de risco para a atividade

2. Estimar a carga mecânica sobre a articulação do ombro.

3. Avaliar a atividade muscular dos músculos tríceps e flexor do punho.

4. Verificar a ocorrência de fadiga muscular durante a realização da tarefa. 
O trabalho humano é um fenômeno complexo e multidimensional, uma realidade do nosso cotidiano que se constitui como objeto de fundamental importância nos aspectos psicológico, sociológico, antropológico e econômico (ABRAHÃO \& PINHO, 2002). Segundo FERREIRA (2002), o trabalho enquanto atividade é fundador da própria existência humana.

"Apesar de a palavra trabalho significar no latim "pena ou servidão do homem à natureza", o trabalho ao longo da história transformou-se em ação produtiva, ocupação e para muitos, algo gratificante em termos existenciais" (ZANDOMENEGHI, 1999, p 21)

Da Idade Média aos tempos atuais ocorreu uma grande evolução tecnológica, ao longo do tempo a força motriz humana e animal foram sendo substituídas pela energia elétrica, mecânica, química, etc. (ANTONIO, 2003). Hoje, o trabalho vem se tornando cada vez mais fragmentado, monótono e repetitivo, com uma carga que vem exigindo um maior envolvimento psicofisiólogico do ser humano e o aumento se sua responsabilidade nas atividades (FERREIRA, 2002). Essas condições de trabalho determinadas por este novo desenho projetaram modelos de gestão sob a lógica do determinismo tecnológico. Nesse cenário, surge o desafio para as ciências que estudam o trabalho, identificar as diferentes necessidades (políticas, sociais, materiais e culturais) determinando o rearranjo de competências no contexto da nova divisão sociotécnica do trabalho (ABRAHÃO \& PINHO, 2002).

Dentro deste contexto sociotécnico de trabalho, a variável indivíduo apresenta duas dimensões complementares que orientam sua investigação: a diversidade individual e a variabilidade intra e inter-individual. As tarefas podem ser iguais ou padronizadas, mas os sujeitos diferem entre si.

A diversidade interindividual se manifesta de diferentes formas, nos aspectos gênero, idade e dimensões corporais, até características menos visíveis como personalidade e experiências dentro e fora do local de trabalho, mas além da diversidade interindividual, a variabilidade intra-individual constitui outra dimensão para se compreender a noção de indivíduo (FERREIRA, 2002).

FERREIRA (2002) chama atenção para a importância de se considerar o estado pessoal de cada sujeito em função do tempo. Essas variações repercutem no 
modo de agir e na conduta no trabalho em termos físicos (postura, gestos, movimentos), cognitivos e afetivos.

Esses conhecimentos quando confrontados de forma integrada contribuem para a organização do trabalho na definição da melhoria desta realidade. Na prática, para produzir e formular conhecimentos para a análise das situações reais de trabalho ou melhorar a relação homem-trabalho, a Ergonomia busca conhecimentos científicos de várias áreas (Antropometria, Fisiologia, Psicologia, Sociologia e Biomecânica) aplicando-os com vistas às transformações do trabalho (ABRAHÃO \& PINHO, 2002).

LAVILLE (1977) representa a atividade do homem no trabalho por um modelo simples que descreve as relações do trabalhador com sua tarefa (FIGURA 1).

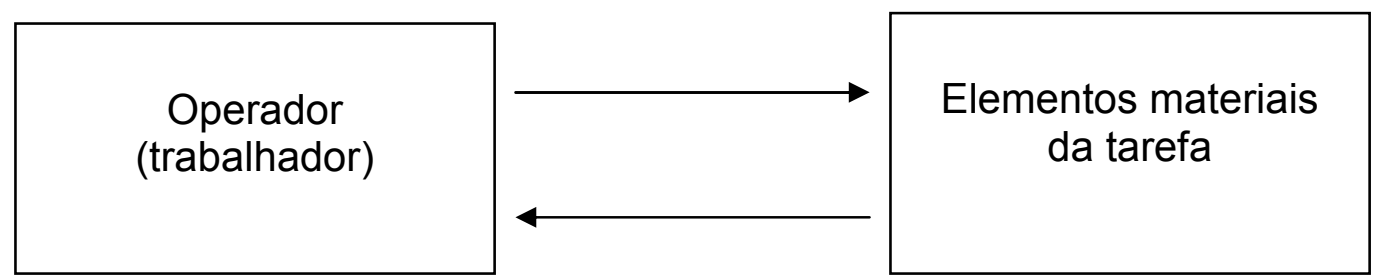

FIGURA 1 - Modelo do sistema homem-tarefa

O esquema pode ser aplicado à maioria dos postos de trabalho e demonstra que o homem e a tarefa não podem ser dissociados quando estudados, mas sim analisados em conjunto, pois as relações entre o homem e sua tarefa são influenciadas por inúmeros fatores modificando desta forma a carga de trabalho, assim definida, como sendo "a medida quantitativa ou qualitativa do nível de atividade (mental, sensório-motora, fisiológica etc.)"

"O homem é um dos elementos que deve ser considerado, e sua atividade está diretamente ligada à eficácia do conjunto do sistema. Para resolver os problemas levantados por uma situação de trabalho, é necessário saber, não apenas as características funcionais separadas da percepção do pensamento e da ação do homem no trabalho, mas sua atividade como um todo, levando em consideração todos os fatores dos quais depende esta atividade" (ZANDOMENEGHI, 1999, p 22) 
$\mathrm{Na}$ análise da atividade consideram-se as características dos trabalhadores, os elementos do ambiente de trabalho e como estes são apresentados aos operadores e percebidos por eles. É um processo que compreende a utilização de recursos instrumentais correntes das metodologias de análise de trabalho, tendo como diferencial a análise em situação real, com o objetivo de identificar o que, como e porque do trabalho dos operadores (ABRAHÃO \& PINHO, 2002).

\subsection{Ergonomia e biomecânica ocupacional}

O termo ergonomia é derivado do grego ergon (trabalho) e nomos (regras) (DUL \& WEERDMEERSTER, 1995). A ergonomia é o estudo da adaptação do trabalho ao homem, sendo o trabalho aqui entendido como toda a situação em que ocorre o relacionamento entre o homem e uma atividade produtiva, ela inicia-se com o estudo das características do trabalhador para, depois, projetar o trabalho executado por ele, procurando sempre preservar a sua saúde (LIDA, 2005).

Desta maneira, a ergonomia parte do conhecimento do homem para projetar o trabalho, baseando-se em diversas áreas científicas, biomecânica, fisiologia, psicologia, engenharia, desenho, informática (DUL \& WEERDMEERSTER, 1995; LAVILLE, 1977; LIDA, 2005).

Em diversos aspectos, o homem pode ser comparado a uma máquina, todavia a máquina humana tem pouca capacidade de desenvolver força, pois seu sistema osteomuscular o habilita a realizar movimentos rápidos e de grandes amplitudes contra pequena resistência (LIDA, 2005). A biomecânica ocupacional preocupa-se com esta desigualdade entre a capacidade física humana e desempenho manual requerido no trabalho, estuda a interação física entre os trabalhadores e suas ferramentas, máquinas e materiais, a fim de aumentar o desempenho e reduzir os riscos dos distúrbios osteomusculares.

Um amplo conhecimento de biomecânica ocupacional é essencial para o entendimento dessas enfermidades, bem como o desenvolvimento de estratégias válidas e efetivas de prevenção que permitirão aos trabalhadores desempenhar suas 
atividades com segurança, dentro de suas capacidades, durante sua vida inteira de trabalho (CHAFFIN, ANDERSSON \& MARTIN, 1997)

CHAFFIN, ANDERSSON e MARTIN (1997) também afirmam que a ergonomia é um meio racional e sistemático de ajustar o trabalho ao homem, tendo como meta primária propiciar melhora no desempenho e segurança ao trabalhador, por meio do estudo e desenvolvimento de princípios gerais que governam a interação das pessoas em seus ambientes de trabalho. Como tal, a ergonomia tende a ser uma disciplina muito mais ampla que a biomecânica ocupacional, sendo ambas altamente relacionadas e complementares.

A ergonomia se mostra como instrumento que avalia e analisa a situação do homem no trabalho, procura remover aspectos que a curto ou longo prazo possam provocar ineficiência ou incapacidade ao trabalhador (WISNER, 1987). Estuda os diversos fatores que influem no desempenho do sistema produtivo, abordando certas características específicas, tais como:

FÍSICA - Ocupa-se das características da anatomia, antropometria, fisiologia e biomecânica, relacionados com a atividade física (postura, manuseio de materiais, movimentos repetitivos, distúrbios musculoesquelético, segurança e saúde).

COGNITIVA - Ocupa-se dos processos mentais, como percepção, raciocínio, e resposta motora, relacionados com as interações entre as pessoas e outros elementos de um sistema.

ORGANIZACIONAL - Ocupa-se da otimização dos sistemas sócio-técnicos, abrangendo as estruturas organizacionais, políticas e processos (LIDA, 2005).

O posto de trabalho é um dos elementos componentes do sistema de produção. A tarefa atribuída e a maneira como é executada dependem de outras tarefas, com as quais entra em relação direta quando se trata de um trabalho em equipe, ou indireta quando se recebe ou se fornece partes do trabalho a outros. Assim, os distúrbios osteomusculares como doenças ocupacionais devem ser analisados dentro do trinômio homem, máquina e ambiente de trabalho.

É importante destacar a necessidade da abordagem dos problemas osteomusculares nos diferentes ambientes de trabalho, com o objetivo de analisar as causas que motivam a ocorrência destes fatos e de propor medidas que estejam encaminhadas às suas reduções ou eliminações. Neste contexto é que a Ergonomia, 
como ciência, tem um papel preponderante na análise e solução de problemas (TAUBE, 2002).

\subsection{O membro superior}

A mão é "o instrumento dos instrumentos" como disse Aristóteles, é dotada de uma grande riqueza funcional que lhe permite uma superabundância de movimentos. Do ponto de vista fisiológico a mão representa a extremidade realizadora do membro superior que constitui o seu suporte e lhe permite adotar a posição mais favorável para uma ação determinada (KAPANDJI, 2000)

O membro superior é um sistema complexo e delicado de estruturas que envolvem diversos músculos, tendões e ramificações nervosas, capaz de realizar variados movimentos como: abertura e fechamento da mão; preensão e pinçamento de objetos; flexão, extensão, desvio ulnar e radial da mão; pronação e supinação; flexão e extensão do braço e antebraço; adução e abdução do braço (COUTO \& MORAES, 2003)

Para a realização de todos esses movimentos, todas as estruturas interagem numa relação de tal proximidade e complexidade que, se por um lado permite todo o potencial citado, por outro confere ao membro superior do ser humano uma vulnerabilidade às lesões.

SNOOK, CIRIELLO e WEBSTER (1999) quantificaram os esforços máximos aceitáveis para movimentos de pinçar, comumente usados durante operações leves de montagem em instalações industriais e operações manuais de embalagem na indústria de alimentos. Os resultados desta experiência mostraram que os torques máximos aceitáveis de extensão do punho com movimento de pinçar são substancialmente mais baixos que os torques máximos do punho em flexão.

PINZKE, STÅL e HANSSON (2001) quantificaram a carga de trabalho no membro superior para tarefas fundamentais durante a ordenha de vacas. A atividade muscular do bíceps braquial e dos flexores do antebraço, assim como posições e movimentos dos pulsos foram simultaneamente medidos por eletromiografia e eletrogoniometria enquanto o trabalho era filmado. O objetivo do estudo foi obter dados para melhorias técnicas do equipamento de ordenha e diminuição do risco de 
doenças do braço punho e mão.

SESTO et al. (2004) investigou mudanças nas propriedades mecânicas do membro superior humano exposto a movimentos repetitivo com esforço excêntrico submáximo de curta duração e concluiu que essas mudanças podem afetar negativamente a capacidade do braço em reagir a cargas elevadas rápidas durante atividades de trabalho o que sugere tensão mecânica no membro superior.

HOSTENS e RAMON (2005) realizaram um estudo para determinar se os músculos trapézio e deltóide sofreriam quaisquer mudanças fisiológicas devido ao trabalho repetitivo e o possível desenvolvimento de fadiga muscular na atividade de guiar um carro por uma hora. Rigidez muscular foi observada em mais da metade dos sujeitos depois de uma hora guiando.

O complexo anatômico e funcional do membro superior é muitas vezes mal utilizado na rotina de trabalho e este delicado e harmônico arranjo de peças nobres, frequentemente sofre pancadas com ferramentas e efetua movimentos forçados (LIDA, 2005)

\subsection{Distúrbios osteomusculares relacionados ao trabalho}

O trabalho mecânico, cada vez mais automatizado passou, progressivamente a exigir maior destreza das mãos. Em meados do século passado, as exigências do trabalho fizeram-se universais, atingido todas as atividades econômicas e categorias de trabalhadores. Neste mesmo ritmo, as Lesões por Esforço Repetitivo LER atingiram todas as categorias de trabalhadores e passaram a ocorrer tão frequentemente que se tornaram um problema de saúde pública. (MPAS, 2003; RIBEIRO, 1997).

\subsubsection{Terminologia e conceitos}

Enfermidades ligadas aos membros superiores podem ser definidas em termos gerais como síndromes caracterizadas por desconfortos, enfraquecimento, incapacidade e dor persistente nas articulações, músculos e outros tecidos moles, 
com ou sem manifestações físicas, (KROEMER, 1989) ${ }^{1}$ apud (MALCHAIRE, COCK, PIETTE, LEAO, LARA \& AMARAL, 1997)

A linguagem empregada sobre o tema ainda é bastante confusa e de terminologia variada. Há uma vasta nomenclatura na literatura para se intitular este tipo de enfermidade (ARAÚJO \& PAULA, 2003; PRZYSIEZNY, 2000; RIBEIRO, 1997; YENG, TEIXEIRA, ROMANO, PICARELLI, SETTIMI \& GERVE, 2001):

- Distúrbios ou Desordens por Trauma Cumulativo

- Síndrome da Sobrecarga Ocupacional

- Síndrome do Esforço Repetitivo

- Distúrbios Músculo Esquelético Ocupacionais

- Síndrome Ombro-Braço

- Síndrome do Membro Superior

- Síndrome de Hipersolicitação

- Síndrome da Dor Crônica do Membro Superior

- Lesões de Sobrecarga Ocupacional

- Lesões por Traumas Cumulativos

- Lesões por Esforço Repetitivo

- Cumulative Trauma Disorders - Estados Unidos

- Repetition Strain Injuries - Austrália e Canadá

- Occupational Cerviocobrachial Disorder - Japão

- Occupational Overuse Syndrome - Austrália

- Lésions Attribuables au Travail Répétitif - França e Canadá

- Work-Related Musculoskeletal Disordres: atualmente mais disseminada no mundo

Adotou-se no Brasil o termo: Distúrbios Osteomusculares Relacionados ao Trabalho (DORT), tradução escolhida pela Previdência Social Brasileira da terminologia Work-Related Musculoskeletal Disordres (WMSD) em substituição ao termo LER. O termo foi justificado no Diário Oficial da União (DOU) de 11 de julho de

\footnotetext{
${ }^{1}$ KROEMER, K. H. E. Cumulative traumas disorders, their recognition and ergonimics measures to avoid them. Applied Ergonomics, Nottingan v.20, n.4, p.274-280. 1989.
} 
1997, sob a alegação de que serviria para identificar atividades profissionais que exigiam movimentos manuais repetitivos, rápidos, vigorosos e combinados a um ambiente inadequado ergonomicamente. Essa alteração corresponde ao que se percebe na prática, ao fato de os distúrbios ocorrerem numa fase precoce e as lesões mais tardiamente (ANTONIO, 2003).

PUTZ-ANDERSON (1988) define doenças musculoesqueléticas como Distúrbios por Traumas Cumulativos (CTD), essas doenças desenvolvem-se gradativamente por períodos de semanas, meses ou anos, como resultado de esforços repetitivos em uma determinada região do corpo. Esta concepção baseia-se na teoria de que cada atividade repetida produz no corpo algum trauma, ou desgaste nos tecidos ou articulações envolvidos no movimento.

Para LIMA (2001) apud (ARAÚJO \& PAULA, 2003) a LER é um conjunto de doenças que acomete músculos, nervos e tendões juntos ou separadamente, tem característica cumulativa e é sempre precedida de dor ou incômodo. E quando sendo a origem da LER, uma atividade ocupacional, denomina-se de DORT.

Os DORT correspondem a um conjunto de afecções relacionadas às atividades laborativas que acometem músculos, fáscias, tendões, ligamentos articulações, nervos e vasos sanguíneos. As formas clínicas têm como aspectos comuns a dor, as incapacidades funcionais temporária ou permanente (YENG et al., 2001).

De acordo com a instrução normativa do Instituto Nacional de Seguridade Social (INSS) n 98 publicada no DOU em 10 de dezembro de 2003, entende-se por LER/DORT como sendo uma síndrome relacionada ao trabalho, caracterizada pela ocorrência de vários sintomas concomitantes ou não, tais como: dor, parestesia, sensação de peso, fadiga, de aparecimento insidioso, geralmente nos membros superiores, mas podendo acometer membros inferiores (MPAS, 2003).

\subsubsection{Breve histórico}

\footnotetext{
${ }^{2}$ LIMA, I. C. de. Programa específico de reabilitação para Cirurgião-Dentista. Jornal da APCD, São Paulo p. 45, nov. 2001.
} 
As doenças ocupacionais não são recentes em 1717 Bernardini Ramazzini já descrevera os movimentos violentos e irregulares, as posturas inadequadas, a repetitividade do esforço e a sobrecarga sobre as estruturas dos membros superiores entre os artesãos escriturários (PRZYSIEZNY, 2000; RIBEIRO, 1997; YENG et al., 2001). Essa condição ficou conhecida como "paralisia do escrivão" e posteriormente como "câimbra do escrevente" para explicar o quadro de dor, parestesia e fadiga nos braços (ARAÚJO \& PAULA, 2003).

Em 1780, os telegrafistas começaram a apresentar sinais de sofrimento relacionados ao trabalho devido ao acionamento de uma tecla repetidas vezes. Em 1833, na Inglaterra, foi documentada a primeira epidemia de "câimbra do escrevente" no serviço britânico civil (ARAÚJO \& PAULA, 2003; PRZYSIEZNY, 2000).

Em 1918, na Suíça, datilógrafos, mecanógrafos e telegrafistas apresentaram sintomas semelhantes aos dos telegrafistas do século XIX, tendo sido suas doenças reconhecidas como originárias das atividades laborais (PRZYSIEZNY, 2000; YENG et al., 2001).

Entre 1960 e 1980 no Japão que velozmente avançou na automação industrial, cerca de $10 \%$ dos 1,6 milhões de trabalhadores eram sintomáticos de DORT. Tal fato, segundo historiadores, deveu-se à elevada sobrecarga do trabalho intensivo em alta velocidade, exigida pelas máquinas operadas manualmente, longas jornadas de trabalho e movimentação exagerada dos dedos e membros superiores (RIBEIRO, 1997).

No Brasil, o primeiro relato do problema apareceu na década de 1980, entre 1984 e 1985, quando foram descritos os primeiros casos em bancários que trabalhavam como digitadores (PRZYSIEZNY, 2000; RIBEIRO, 1997). O tema foi abordado pela primeira vez em 1986 no I Encontro Estadual dos Profissionais de Processamento de Dados do Rio Grande do Sul (PRZYSIEZNY, 2000). A primeira referência oficial a esse tipo de enfermidade do sistema músculo-esquelético foi realizada pela Previdência Social, definida como tenossinovite do digitador, por meio de portaria publicada em 06 de agosto de 1987. Em 1992, a Secretaria de Estado da Saúde de São Paulo publicou a resolução SS 197/92, oficializando o termo Lesões por Esforços Repetitivos, sendo o mesmo adotado pelos outros estados brasileiros. Em 1993, o INSS publicou sua Norma Técnica para Avaliação de Incapacidade para 
LER.(RASIA, 2004)

A incidência desses distúrbios tem aumentado constantemente em todo mundo, chegando a alcançar proporções epidêmicas nos países industrializados (GUIDOTTI, 1992; IRELAND, 1998) apud (CÔTÉ, RAYMOND, MATHIEU, FELDMAN \& LEVIN, 2005). Com o avanço da automação o problema começou a aparecer na indústria principalmente nas linhas de montagem, caixas de supermercados, embaladores, auxiliar de enfermagem, dentistas, operários da construção civil, motoristas, operadores de trens, entre outros (MANSFIELD \& MARSHALL, 2001; OLIVEIRA, MORAES, OLIVEIRA \& ABECASIS, 1999; PRZYSIEZNY, 2000; REID, PINDER \& MONNINGTON, 2001; RIBEIRO, 1997).

As estatísticas demonstram um crescente aumento no número de casos de DORT no país, porém as informações do Sistema Único de Saúde (SUS) são deficientes, pois não discriminam os acidentes de trabalho dos DORT, ficando disponíveis as estatísticas fornecidas pelo INSS que se referem apenas aos trabalhadores do mercado formal, ou seja, que apresentam contrato trabalhista, o que totaliza menos da metade da população brasileira economicamente ativa (YENG et al., 2001).

No Brasil, de acordo com o Anuário Estatístico da Previdência Social do ano de 2004, foram registradas 27.587 doenças do trabalho sendo 7.963 classificadas como sinovites e tenossinovites e 3.356 como lesão no ombro, correspondendo estas a $41,03 \%$ do total (MPAS, 2006).

\subsubsection{Etiologia}

Para VIIKARI-JUNTURA (1998) ${ }^{4}$ apud (CÔTÉ et al., 2005) a etiologia dos distúrbios osteomusculares relacionados ao trabalho não é bem conhecida, e tarefas

\footnotetext{
${ }^{3}$ GUIDOTTI, T.L., Occupational repetitive strain injury. American Family Physician $\circledast$. Kansas, v 45, p 585-592, 1992.

IRELAND, D.C.R. Australian repetition strain injury phenomenon. Clinical Orthopaedics \& Related Research, Pennsylvania $\vee 351$, p 63-73. 1998

4 Viikari-Juntura, E. Risk factors for upper limb disorders. Clinical Orthopaedics \& Related Research, Pennsylvania, v 351, p 39-43.590, 1998
} 
com alto número de movimentos repetitivos, posturas inadequadas ou estáticas, desequilíbrio musculares e fadiga têm sido associados ao desenvolvimento desses distúrbios. Existem evidências de que a postura, os movimentos repetitivos, a força exercida e as combinações desses elementos, além da falta de repouso suficiente, são fatores de risco para o desenvolvimento destes distúrbios (MPAS, 2003; PUTZANDERSON, 1988).

Pouco tem sido feito para se estabelecer relações quantitativas de exposição, isto pode ser devido à falta de procedimentos com bases científicas que considerem os valores limites de exposição (FORSMAN, HANSSON, MEDBO, ASTERLAND \& ENGSTROM, 2002).

A etiologia desse conjunto de afecções é complexa, todavia as cargas dinâmicas são geralmente solicitadas aos músculos do braço, antebraço e mão para a execução de tarefas. $E$ as cargas estáticas, ou contrações isométricas mantidas são geralmente requeridas aos músculos do pescoço e da cintura escapular, a fim de manter os membros superiores estáveis em determinadas posições para realizar as tarefas propostas (ARAÚJO \& PAULA, 2003; PRZYSIEZNY, 2000).

Segundo STOCK $(1991)^{5}$ apud (MALCHAIRE et al., 1997) muito poucos estudos científicos têm de fato demonstrado a associação entre doenças do punho e força, repetitividade e posição angular, e a relação destas com o desenvolvimento de enfermidades.

Acreditou-se por muito tempo que apenas os fatores físicos relacionados ao trabalho eram os determinantes na origem dos DORT. Posteriormente, verificouse que o estresse psicológico gerado pelo trabalho também é um determinante, e talvez seja a principal razão pela qual alguns adquirem os distúrbios e outros não, mesmo realizando as mesmas tarefas. Um aumento da tensão muscular e uma queda das resistências corporais, com uma descarga nos pontos mais sensíveis do corpo, podem ser gerados em conseqüência à sobrecarga mental do trabalho (PEREIRA, 2001).

A denominação LER, apesar de mais difundida no Brasil, é criticada por

\footnotetext{
${ }^{5}$ Stock, S. R. Workplace ergonomic factors and the development of musculoskeletal disorders of the neck and upper limbs: a meta-analysis American Journal of Industrial Medicine, New Jersey, v 19, n 1, p 87-107, 1991.
} 
reduzir os fatores causais aos movimentos repetitivos e negligenciar a importância de outros fatores que levam a doença (ANTONIO, 2003)

YENG et al.( 2001) afirmam que em nossa cultura o conceito de doença está ligado ao determinismo biológico, e existe a proposta de que a tensão muscular secundária ao estresse poderia, em parte, ser responsável pela ligação entre fatores psicossociais e doenças musculoesqueléticas.

\subsection{Método RULA}

Um método fácil de investigação desenvolvido para avaliar a exposição do indivíduo a fatores de risco relacionados a enfermidades dos membros superiores e de grande aplicabilidade é o"Rapid Upper Limb Assessment" (RULA) (MCATAMNEY \& CORLETT, 1993)

Este método possui a vantagem de não interferir na situação de trabalho e de não solicitar habilidades prévias para sua aplicação, pois se trata de uma análise observacional, que fornece um sistema de classificação de níveis de ação indicando a necessidade de intervenção no controle dos fatores de risco.

O RULA avalia a exposição aos fatores de risco por meio de diagramas posturais e tabelas. Os seguintes fatores foram descritos por McPHEE (1987) ${ }^{6}$ apud (MCATAMNEY \& CORLETT, 1993)

- Número de movimentos

- Posição estática

- Força

- Postura de trabalho determinada pelos equipamentos

- Tempo de trabalho sem interrupção

Identificar o esforço muscular que pode contribuir para fadiga associado à postura de trabalho (posição estática ou movimentos repetitivos), bem como obter resultados para uma ampla avaliação ergonômica envolvendo fatores físicos, mentais, ambientais, epidemiológicos e organizacionais, também é possível através

\footnotetext{
${ }^{6}$ McPHEE, B. J. Work-related musculoskeletal disorders of the neck and upper extremities in workers engaged in light, highly repetitive work in Osterholz, U. ; Karmau, W. ; Hullman, B. and Ritz, B. (eds) Proc Int Symp Work-related Musculoskeletal Disorders, Bonn 1987 p 244-258
} 
deste método.

A base para criação do RULA foi desenvolvida pelo método OWAS (Ovako Working Posture Analyzing System) que utiliza números para representar as posturas associados a um sistema de codificação e critérios biomecânicos e de função muscular, que classificam cada combinação postural da menor para maior carga (MCATAMNEY \& CORLETT, 1993)

No método RULA, o corpo humano é dividido em dois grupos $A$ e $B$, sendo incluídos no grupo $A$, os membros superiores (braço, antebraço e punho) e no grupo B o pescoço, tronco e membros inferiores.

Segundo MCATAMNEY e CORLETT (1993), a classificação para o grupo A, relativa ao braço, baseou-se nos estudos realizados por TICHAUER (1966), CHAFFIN (1973), HERBERTS et al. (1980), HAGBERG (1981), SCHULDT et al. (1987), e HARMS-RINGDAHL e SCHULDT (1990). Para o antebraço os trabalhos de GRANDJEAN (1988) e TICHAUER (1966) e para o punho as Normas Britânicas de Saúde e Segurança Executiva.

$\mathrm{Na}$ intenção de promover uma ferramenta de rápida aplicação, alguns detalhes foram excluídos do método RULA, como a avaliação postural dos dedos. No entanto a força exercida pelos dedos é registrada como parte do procedimento de avaliação.

MCATAMNEY e CORLETT (1993) relatam também em estudos recentes que o baixo nível de cargas estáticas está associado à fadiga muscular. BJÖRKSTÉN e JONSSON (1977) mostraram que força muscular estática mantida durante o trabalho por mais de 1 hora não deve exceder 5 a $6 \%$ da contração voluntária máxima (CVM). JONSSON (1982) também sugeriu que cargas estáticas são aceitáveis se estiverem abaixo de 2\% da CVM quando mantidas por um dia inteiro de trabalho.

GRANDJEAN (1988) ${ }^{7}$ apud (MCATAMNEY \& CORLETT, 1993) quantificou cargas estáticas em três categorias relacionadas com a força requerida: alta força deve ser exercida numa ação muscular por menos de 10 segundos, força moderada por menos que 1 minuto e uma baixa força por menos que 4 minutos.

\footnotetext{
${ }^{7}$ GRANDJEAN, E. Fitting the task to man. London: Taylor \& Francis, 1988.
} 


\subsection{Dinâmica inversa}

Para a medida direta das forças internas atuantes nos segmentos corporais se faz necessário realizar incisões e assim medir diretamente a tração tendínea do músculo. Esse procedimento é invasivo, o que inviabiliza a grande maioria dos estudos, então são utilizadas técnicas menos invasivas e mais indiretas para avaliar a força muscular. Desta forma muitas técnicas analíticas e experimentais têm sido desenvolvidas para contornar esse problema

Considerando o corpo humano como um sistema de segmentos rígidos interligados pelas articulações, sendo estas estruturas passivas e os músculos os componentes ativos do sistema, e supondo que todas as forças produzidas sobre as articulações passam através dos centros articulares e que os músculos são os únicos elementos que produzem força excêntrica (distante do eixo) sobre estes centros, podemos avaliar a interação entre os segmentos por meio de um procedimento denominado dinâmica inversa.

Segundo (BUCHANAN, LLOYD, MANAL \& BESIER, 2005), existem dois modelamentos tradicionais para o estudo da biomecânica do movimento humano: a dinâmica direta e a dinâmica inversa. Na dinâmica inversa o problema é solucionado pelo ponto final, ou seja, medindo-se a posição dos segmentos e as forças externas que agem sobre o corpo.

A dinâmica inversa permite o cálculo das resultantes das forças musculares nas articulações. O processo consiste em obter a descrição cinemática do movimento, os dados antropométricos do modelo anatômico e as medidas de forças externas ao sistema para construir as equações do movimento usando as Leis da Física derivadas da cinemática.

Por meio da cinemática do movimento podemos deduzir as equações para a determinação das forças e momentos intersegmentares. Utiliza-se, então, um diagrama de corpo livre que proporciona a visão de um corpo, ou parte dele, como uma entidade isolada no espaço.

O diagrama de corpo livre é uma técnica analítica que reduz a complexidade por meio de uma representação simplificada, na qual todas as forças 
externas que influenciam o sistema são identificadas separadamente para cada segmento (ENOKA, 2000). A dinâmica inversa juntamente com o modelamento do corpo em segmentos articulados apresenta-se como a alternativa mais adequada em termos de viabilidade para a determinação das forças internas (HIRATA, 2005).

\subsection{Eletromiografia}

Células excitáveis, como aquelas que compõem o tecido muscular, produzem potenciais bioelétricos quando estimuladas (HWANG, 2006). Esses potenciais podem ser captados extracelularmente por meio de eletrodos inseridos no músculo, ou à distância, por eletrodos afixados na superfície da pele sobre o músculo em estudo. O conjunto de técnicas utilizadas no estudo da atividade elétrica muscular, em que estão associados à captação, amplificação, filtragem, aquisição, quantificação, análise e interpretação define-se como eletromiografia. Eletromiograma (EMG) é o termo usado para indicar a atividade elétrica muscular captada por eletrodos (KOHN \& MEZZARANE, 2005)

O EMG é a somação algébrica de todos os sinais detectados, podendo ser afetado por propriedades musculares, anatômicas e fisiológicas, como também pelo controle do sistema nervoso periférico e pela instrumentação utilizada para a aquisição dos sinais (DE LUCA, 1997; ENOKA, 2000; MARCHETTI, 2004)

A eletromiografia de superfície (SEMG) é usada muitas vezes para o estudo de atividades ocupacionais, avaliação de tarefas industriais e também para investigar fadiga muscular, observada pela deficiência na manutenção da força requerida ou esperada, acompanhada de alterações na atividade elétrica muscular e de mudanças nas características espectrais do EMG, com o aumento na amplitude e decréscimo da freqüência do sinal adquirido (CHAFFIN, ANDERSSON \& MARTIN, 1997; DE LUCA, 1997; DIMITROVA \& DIMITROV, 2003; NIOSH, 1990; 1997).

A modificação espectral do EMG e a depreciação da manutenção da força estão inevitavelmente relacionadas durante a fadiga, todavia não se sabe se este relacionamento é causal (DE LUCA, 1997). 


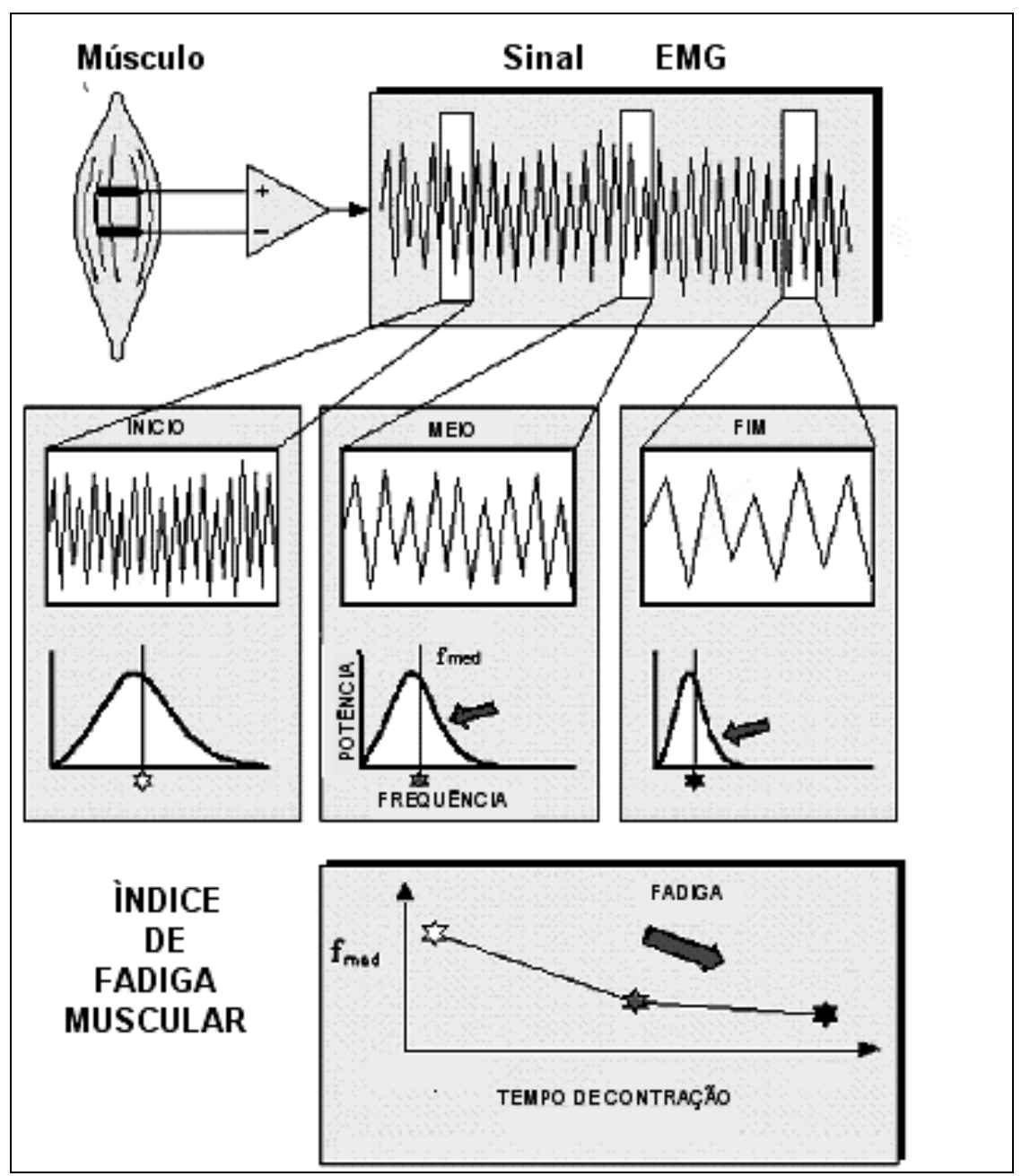

FIGURA 2 - Diagrama das alterações espectrais que ocorrem com o sinal EMG durante contrações sustentadas. Adaptado de DE LUCA (1997).

Em estudos de Biomecânica, é freqüentemente desejável avaliar a fadiga de músculos envolvidos no desempenho de uma tarefa. DE LUCA (1997) afirma que o ponto de falência (o ponto em que uma contração não pode mais ser mantida) é função tanto de fatores fisiológicos como psicológicos, sendo este de difícil identificação, e sugere como alternativa na identificação de fadiga, explorar a propriedade espectral do EMG. Características do sinal EMG que quantificam as modificações espectrais, tais como mediana, média e moda, durante contrações sustentadas, são indicadores que podem ser utilizados em fornecem índices de fadiga. Na FIGURA 2 é mostrado um diagrama destas alterações espectrais que ocorrem com o sinal EMG durante contrações sustentadas. 
DE LUCA (1997) descreve que a freqüência mediana é preferível a outros indicadores porque ele é menos sensível ao ruído, ao alisamento do sinal, e na maioria de casos é mais sensível aos fatores fisiológicos e bioquímicos que ocorrem dentro dos músculos durante contrações sustentadas.

\section{MATERIAL E MÉTODOS}

Este estudo caracterizou-se por uma pesquisa quase-experimental, observacional de corte transversal.

\subsection{Amostra experimental}

A coleta de dados foi realizada na Companhia Brasileira de Trens Urbanos (CBTU) exclusivamente na Superintendência de Recife, onde existe uma população composta por 77 maquinistas (operadores) de trem; 71 homens e seis mulheres. A população estudada tem jornada de trabalho de seis horas e cinco minutos em regime de escala $5 \times 1 \times 2 \times 3$, sendo cinco dias no turno da manhã (05:00 às 11:05 $\mathrm{h}$ ) ou da tarde(11:00 às 17:05 h) ou vespertino (17:00 às 23:05 h), e uma folga, seguida de dois dias no turno noturno (22:00 às 06:00 h) e após este turno, três folgas.

Uma amostra composta por 10 operadores voluntários, do sexo masculino, com faixa etária de $40 \pm 4$ anos, envergadura de $178 \pm 10 \mathrm{~cm}$ e tempo de atividade de $16 \pm 2$ anos foi avaliada. Estudamos uma amostra de somente 10 sujeitos da população de 77 operadores em virtude da complexidade das medidas realizadas e da disponibilidade dos sujeitos para serem voluntários na pesquisa.

\subsection{Procedimentos}

Inicialmente, após as devidas explicações cada sujeito assinou o Termo de consentimento livre e esclarecido (protocolo $n^{\circ}$ 2006/18), aprovado pelo comitê de ética da Escola de Educação Física e Esporte da Universidade de São Paulo e respondeu a versão brasileira do Questionário Nórdico de Sintomas Osteomusculares (QNSO). 
Em seguida foram retiradas as medidas antropométricas do comprimento da mão, antebraço, braço e envergadura de acordo com GUEDES e GUEDES (2005). O passo seguinte foi o registro, por meio de fotografia, das posturas nos pontos de tração. Esta etapa foi realizada com o trem estacionado no pátio de manobras.

Em operação comercial, foi efetuado o registro da atividade elétrica muscular em quatro momentos distintos: $(A)$ - inicio da primeira volta; $(B)$ - final da primeira volta; (C) - início da terceira volta e (D) - final da terceira volta. Posteriormente a tarefa de condução do trem foi filmada por 30 minutos.

Foram incluídos apenas sujeitos aptos à realização da tarefa, sem queixas de dores ou qualquer outra enfermidade ligada ao membro superior esquerdo e que tiveram no mínino 72 horas de repouso.

\subsection{Tarefa}

A postura do maquinista na atividade de condução do trem caracteriza-se inicialmente pela posição do membro superior esquerdo totalmente estendido afastado da linha média do corpo com o braço em abdução no plano escapular em torno de $40^{\circ} \mathrm{com}$ a horizontal, e cotovelo estendido, pressionando o manete para baixo, o que corresponde ao ponto de tração 0 (zero), como observado na FIGURA 3. Para que ocorra movimentação do trem, é necessário que o manete de tração seja movimentado no sentido horário, fazendo com que o mesmo atinja os pontos de tração 1, 2, 3, 4 respectivamente, correspondendo ao aumento da aceleração da composição metroferroviária.

Este manete é operado pelo membro superior esquerdo e equipado com sistema de segurança, um interruptor elétrico que deve permanecer fechado durante a condução, obrigando o operador a uma constante contração isométrica na musculatura posterior do braço, como também movimentos de flexão e extensão do cotovelo com o ombro em abdução, durante a aceleração do trem. 


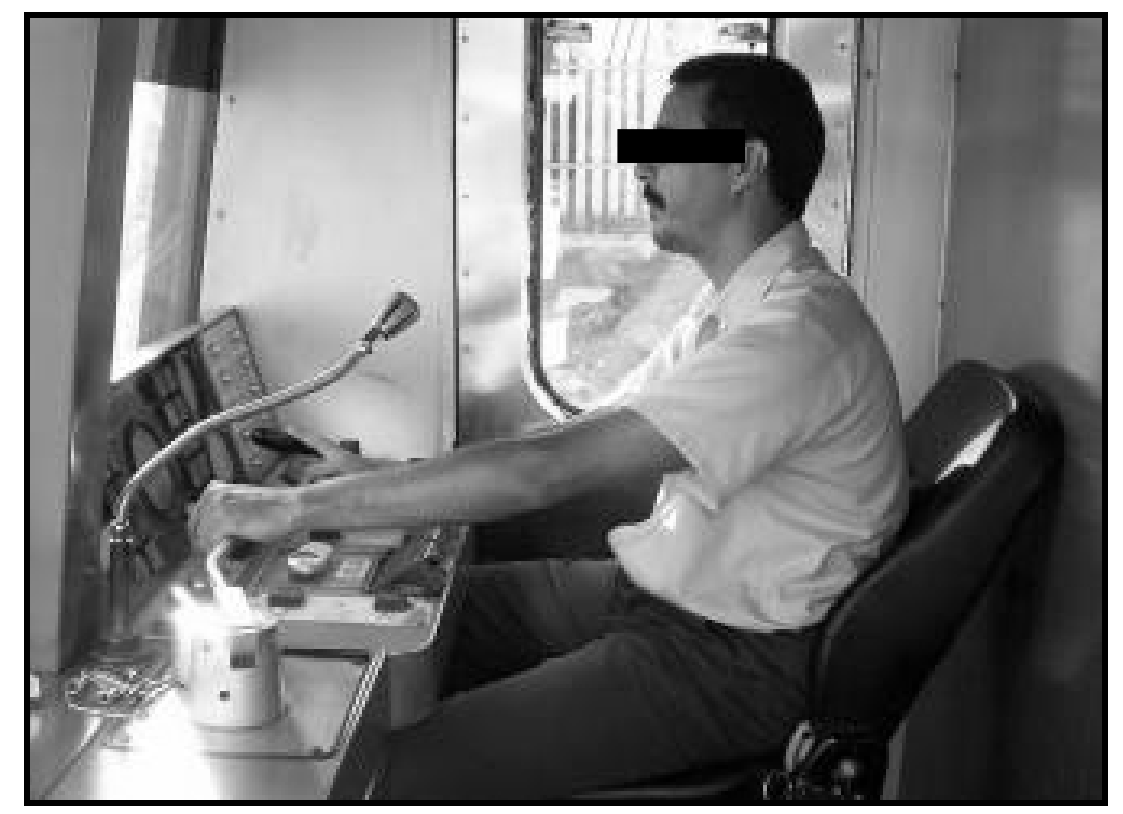

FIGURA 3 - Postura do maquinista durante o trabalho

Em um questionário aplicado entre os próprios maquinistas, de um total de 77 sujeitos, 58 responderam. Observou-se a presença de dores no ombro, cotovelo e punho em 48 sujeitos, 16 maquinistas foram afastados para tratamento com ônus para a empresa. Como justificativa pela baixa procura a ajuda médica ocupacional, foram obtidas algumas respostas como:

"Porque não queria correr o rico de ser afastado."

"Não procurei porque as dores eram pequenas."

"Por não acreditar em providências por parte do médico... até hoje não houve mudanças satisfatórias no equipamento causador das lesões."

"Por falta de tempo."

"O médico passará um remédio para dor e depois operando o trem a dor voltará." 


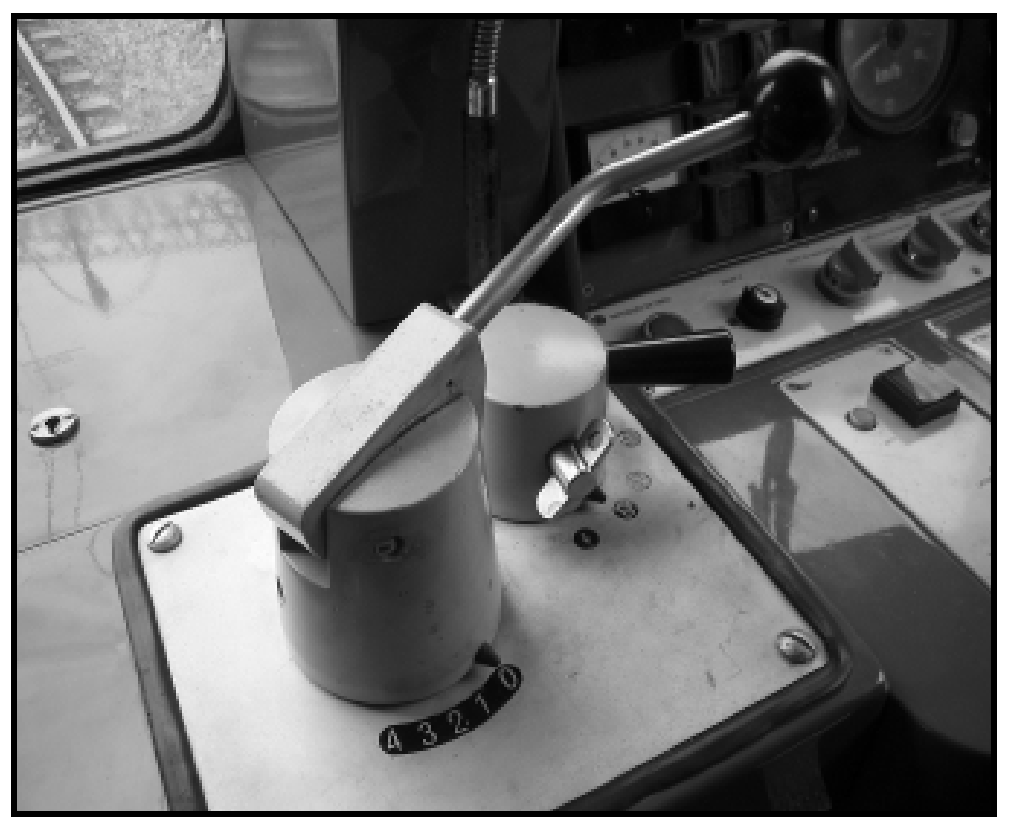

FIGURA 4 - Manete de tração

Devido às paradas nas plataformas das estações para embarque e desembarque dos usuários ao longo do trajeto, o maquinista, durante a condução em operação comercial, realiza sucessivas movimentações do manete de tração tanto no sentido horário como no sentido anti-horário, acelerando ou cortando a tração do trem respectivamente. Isto o obriga a flexionar e estender o cotovelo, variando os ângulos segmentares do braço e da mão com relação a horizontal, ou seja, puxando ou empurrando o manete para próximo ou longe do corpo.

Para este estudo foi solicitado ao maquinista que operasse o manete de tração como de costume, isto é, sempre o mantendo pressionado para baixo, inibindo o dispositivo de segurança e passando pelos pontos de aceleração 0, 1, 2, 3, e 4.

\subsection{Instrumentos}

\subsubsection{Questionário Nórdico de Sintomas Osteomusculares - QNSO}

O Questionário Nórdico de Sintomas Osteomusculares (QNSO), descrito no Anexo II, consiste em escolhas múltiplas ou dicotômicas quanto à ocorrência de sintomas nas diversas regiões anatômicas nas quais são mais comuns. 0 
respondente deve relatar a ocorrência dos sintomas considerando os 12 meses e os sete dias precedentes à entrevista, bem como relatar a ocorrência de afastamento das atividades rotineiras no último ano.

O Questionário apresenta um índice de freqüência de sintomas de dor dormência, formigamento ou desconforto para cada região anatômica, variando entre zero e três para ocorrências nos 12 meses precedentes, em que zero representa a ausência de sintomas; o índice um é atribuído para relato de sintomas raros; o índice dois, para relatos de sintomas freqüentes; e o índice três, quando houver relato de sintomas sempre presentes. As regiões de quadris/coxas, joelhos, tornozelos/pés são combinadas em uma única região anatômica, denominada membros inferiores.

Além das informações sociodemográficas (sexo, idade, escolaridade, estado civil) e da caracterização do processo de trabalho (tempo de atividade, jornada, uso de tabagismo, dominância de membro superior).

\subsubsection{Rapid Upper Limb Assessment - Rula}

Neste método, a classificação dos movimentos para cada parte do corpo é dividida em secções. Estas secções são numeradas de modo que o número um representa movimentos ou posturas com menor fator de risco. Os números aumentam para posturas extremas que indicam aumento da carga no segmento corporal.

Cada segmento corporal é representado no plano sagital (diagramas). Para posturas não representadas no plano sagital, a numeração correspondente é apresentada ao lado do diagrama.

Apenas um escore é requerido para o grupo A e B respectivamente, o qual representará o nível de carga sobre o sistema musculoesquelético nas diversas combinações posturais das partes do corpo (FIGURAS 4 e 5). 


\begin{tabular}{|c|c|c|c|c|c|c|}
\hline \multicolumn{7}{|c|}{ GRUPO A - POSIÇÔES } \\
\hline Escores & 1 & 2 & 2 & 3 & 4 & Ajustes \\
\hline OMBRO & $\begin{array}{c}20^{\circ} \text { de } \\
\text { extensão a } \\
20^{\circ} \text { de flexão }\end{array}$ & $\begin{array}{l}\text { w } \\
>20^{\circ} \text { de } \\
\text { extensão }\end{array}$ & $\begin{array}{l}20 \text { a } 40^{\circ} \text { de } \\
\text { flexão }\end{array}$ & $\begin{array}{l}\left\{\left\{\begin{array}{l}3 \\
.>45 \text { a } 90^{\circ} \mathrm{de} \\
\text { flexão }\end{array}\right.\right. \\
\end{array}$ & 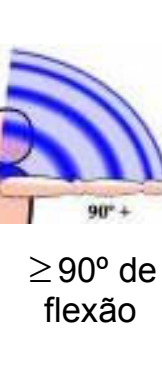 & $\begin{array}{c}\text { +1 se ombro } \\
\text { elevado ou braço } \\
\text { abduzido } \\
\text {-1 se posição de } \\
\text { tronco inclinada } \\
\text { ou peso do braço } \\
\text { suportado }\end{array}$ \\
\hline $\begin{array}{l}\text { ANTE- } \\
\text { BRAÇO }\end{array}$ & $\begin{array}{l}60 \text { a } 100^{\circ} \text { de } \\
\text { flexão }\end{array}$ & $\begin{array}{l}<60^{\circ} \text { de } \\
\text { flexão }\end{array}$ & $\begin{array}{l}\sum_{\text {flexão }} \\
\sum_{100^{\circ}+}\end{array}$ & & & $\begin{array}{l}\text { houver rotação } \\
\text { interna do braço e } \\
\text { antebraço } \\
\text { passando da linha } \\
\text { média do corpo ou } \\
\text { rotação externa do } \\
\text { braço }\end{array}$ \\
\hline PUNHO & $\begin{array}{c}\text { Neutra } \\
\text { ou meia } \\
\text { inclinação de } \\
\text { pronaçãao ou } \\
\text { supinação }\end{array}$ & $\begin{array}{c}0 \text { a } 15^{\circ} \text { de } \\
\text { flexão ou } \\
\text { extensão ou } \\
\text { total pronação } \\
\text { ou supinação }\end{array}$ & & $\begin{array}{l}\geq 15^{\circ} \text { de } \\
\text { flexão ou } \\
\text { extensão }\end{array}$ & & $\begin{array}{c}+1 \text { se em desvio } \\
\text { ulnar ou radial }\end{array}$ \\
\hline
\end{tabular}

FIGURA 5 - Escores de classificacão das posturas do corpo pertencentes ao grupo A Adaptado de www.ergonomics.co.uk/Rula/Ergo/index.html. A"

Rotação do punho 1 - essencialmente na posição de aperto de mão, rotação igual a $0^{\circ} ; 2$ - punho torcido longe da posição de aperto de mão, rotação maior que $0^{\circ}$. 


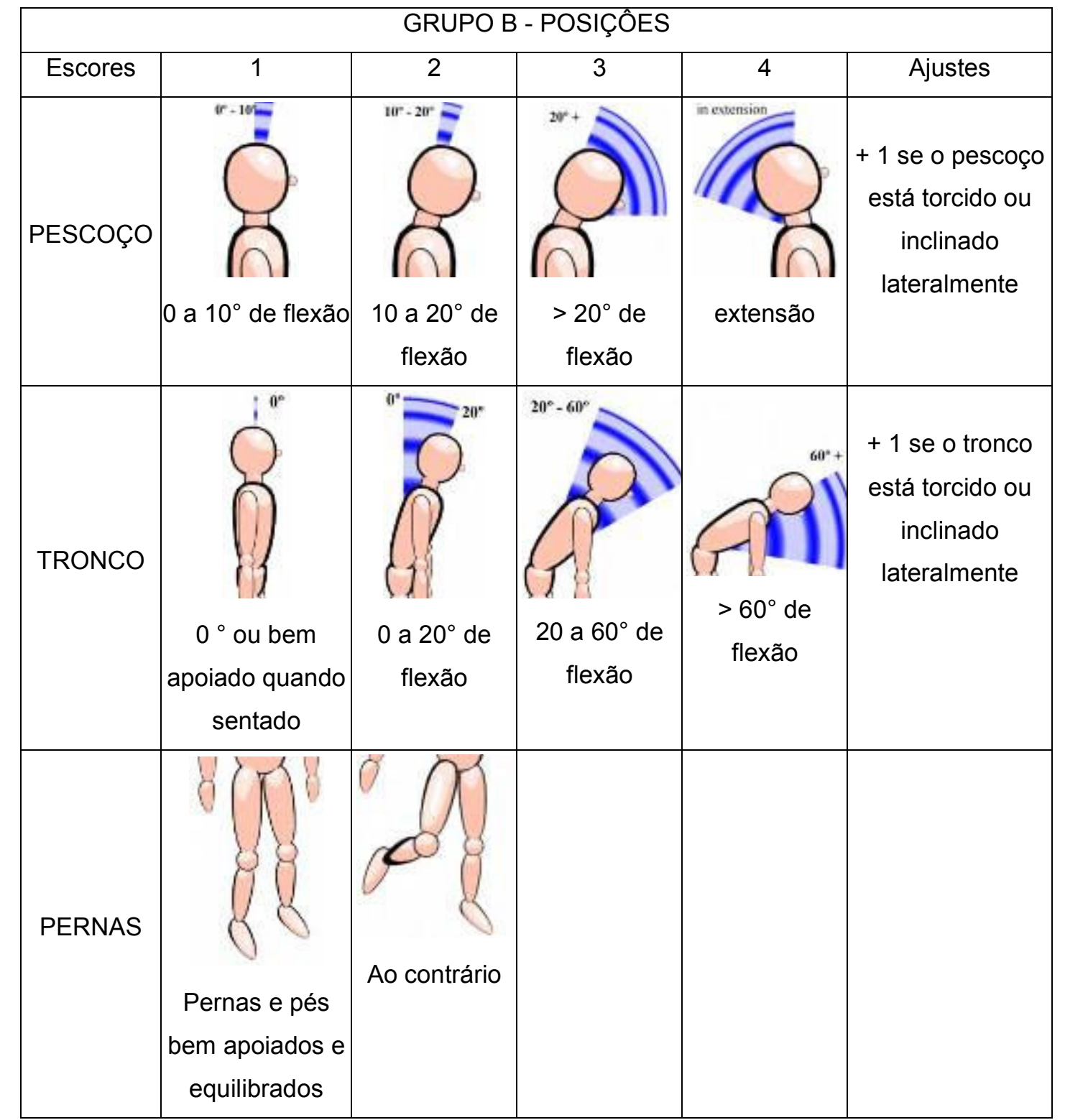

FIGURA 6 -Escores de classificação das posturas do corpo pertencentes ao grupo B. Adaptado de www.ergonomics.co.uk/Rula/Ergo/index.html.

A combinação das posturas individuais para cada grupo origina os escores parciais $A$ e $B$ respectivamente (TABELA 1 e 2 ). 
TABELA 1 - Combinações das posturas individuais das articulações dos membros superiores para determinação do escore A ((MCATAMNEY \& CORLETT, 1993).

\begin{tabular}{|c|c|c|c|c|c|c|c|c|c|}
\hline \multirow{4}{*}{ Ombro } & \multicolumn{9}{|c|}{ Posição do punho } \\
\hline & \multirow{3}{*}{$\begin{array}{l}\text { Ante } \\
\text { braço }\end{array}$} & \multicolumn{2}{|c|}{1} & \multicolumn{2}{|c|}{2} & \multicolumn{2}{|c|}{3} & \multicolumn{2}{|c|}{4} \\
\hline & & \multicolumn{6}{|c|}{ Rotação do punho } & \multirow[b]{2}{*}{1} & \multirow[b]{2}{*}{2} \\
\hline & & 1 & 2 & 1 & 2 & 1 & 2 & & \\
\hline \multirow[t]{3}{*}{1} & 1 & 1 & 2 & 2 & 2 & 2 & 3 & 3 & 3 \\
\hline & 2 & 2 & 2 & 2 & 2 & 3 & 3 & 3 & 3 \\
\hline & 3 & 2 & 3 & 3 & 3 & 3 & 3 & 4 & 4 \\
\hline \multirow[t]{3}{*}{2} & 1 & 2 & 3 & 3 & 3 & 3 & 4 & 4 & 4 \\
\hline & 2 & 3 & 3 & 3 & 3 & 3 & 4 & 4 & 4 \\
\hline & 3 & 3 & 4 & 4 & 4 & 4 & 4 & 5 & 5 \\
\hline \multirow[t]{3}{*}{3} & 1 & 3 & 3 & 4 & 4 & 4 & 4 & 5 & 5 \\
\hline & 2 & 3 & 4 & 4 & 4 & 4 & 4 & 5 & 5 \\
\hline & 3 & 4 & 4 & 4 & 4 & 4 & 5 & 5 & 5 \\
\hline \multirow[t]{3}{*}{4} & 1 & 4 & 4 & 4 & 4 & 4 & 5 & 5 & 5 \\
\hline & 2 & 4 & 4 & 4 & 4 & 4 & 5 & 5 & 5 \\
\hline & 3 & 4 & 4 & 4 & 5 & 5 & 5 & 6 & 6 \\
\hline \multirow[t]{3}{*}{5} & 1 & 5 & 5 & 5 & 5 & 5 & 6 & 6 & 7 \\
\hline & 2 & 5 & 6 & 6 & 6 & 6 & 7 & 7 & 7 \\
\hline & 3 & 6 & 6 & 6 & 7 & 7 & 7 & 7 & 8 \\
\hline \multirow[t]{3}{*}{6} & 1 & 7 & 7 & 7 & 7 & 7 & 8 & 8 & 9 \\
\hline & 2 & 8 & 8 & 8 & 8 & 8 & 9 & 9 & 9 \\
\hline & 3 & 9 & 9 & 9 & 9 & 9 & 9 & 9 & 9 \\
\hline
\end{tabular}


TABELA 2 - Combinações das posturas individuais das articulações dos membros inferiores para determinação do escore B (MCATAMNEY \& CORLETT, $\underline{1993}$

\begin{tabular}{|c|c|c|c|c|c|c|c|c|c|c|c|c|}
\hline \multicolumn{13}{|c|}{ Tronco } \\
\hline & \multicolumn{2}{|c|}{1} & \multicolumn{2}{|c|}{2} & \multicolumn{2}{|c|}{3} & \multicolumn{2}{|c|}{4} & \multicolumn{2}{|c|}{5} & \multicolumn{2}{|c|}{6} \\
\hline \multicolumn{13}{|c|}{ Membros inferiores } \\
\hline Pescoço & 1 & 2 & 1 & 2 & 1 & 2 & 1 & 2 & 1 & 2 & 1 & 2 \\
\hline 1 & 1 & 3 & 2 & 3 & 3 & 4 & 5 & 5 & 6 & 6 & 7 & 7 \\
\hline 2 & 2 & 3 & 2 & 3 & 4 & 5 & 5 & 5 & 6 & 7 & 7 & 7 \\
\hline 3 & 3 & 3 & 3 & 4 & 4 & 5 & 5 & 6 & 6 & 7 & 7 & 7 \\
\hline 4 & 5 & 5 & 5 & 6 & 6 & 7 & 7 & 7 & 7 & 8 & 8 & 8 \\
\hline 5 & 7 & 7 & 7 & 7 & 7 & 8 & 8 & 8 & 8 & 8 & 8 & 8 \\
\hline 6 & 8 & 8 & 8 & 8 & 8 & 8 & 8 & 9 & 9 & 9 & 9 & 9 \\
\hline
\end{tabular}

Para cargas adicionais no sistema musculoesquelético causadas por trabalhos excessivamente estáticos, ou repetidos, ou ainda solicitação de força para manter uma carga externa, acrescenta-se aos escores A ou B:

- Um, se a postura é mantida estática por mais de um minuto ou se a atividade é repetida mais que quatro vezes por minuto.

- Se a carga ou a força é menor ou igual a dois quilogramas - força $(\mathrm{kgf})^{8}$ e mantida intermitentemente o escore adicional é zero, se de dois a 10 kgf o escore é um.

- Cargas ou forças de dois a $10 \mathrm{kgf}$ mantidas estáticas ou repetidas ou maior que $10 \mathrm{kgf}$ intermitente o escore adicional é dois.

- E cargas ou forças maiores que $10 \mathrm{kgf}$ exercidas estaticamente ou repetidamente o escore correspondente é três.

Esses valores adicionais foram baseados nos estudos de PUTZANDERSON (1988) e STEVENSON e BAIDYA (1987).

Conforme o trabalho muscular empregado e a força exercida durante a realização da tarefa, os valores adicionais são somados aos escores parciais $A$ e B originando os escores parciais C e D (FIGURA 7).

Outra combinação entre os escores C e D define o escore final da

\footnotetext{
${ }^{8} 1 \mathrm{kgf}$ é igual a aproximadamente 9,8 Newton $(\mathrm{N})$.
} 
atividade analisada, indicando a graduação da sobrecarga musculoesquelética e necessidade ou não de uma intervenção nas posturas adotadas durante o trabalho.

TABELA 3 - $\underline{\text { Cruzamento dos escores parciais C e D para determinação do escore }}$ final

\begin{tabular}{|c|c|c|c|c|c|c|c|c|}
\hline & \multicolumn{8}{|c|}{ Escore parcial D (pescoç, uronco, permas) } \\
\hline \multirow{5}{*}{ 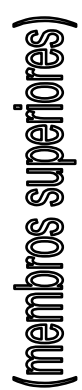 } & & 1 & 2 & 3 & 4 & 5 & 6 & 7 \\
\hline & 1 & 1 & 2 & 3 & 3 & 4 & 5 & 5 \\
\hline & 2 & 2 & 2 & 3 & 4 & 4 & 5 & 5 \\
\hline & 3 & 3 & 3 & 3 & 4 & 4 & 5 & 6 \\
\hline & 4 & 3 & 3 & 3 & 4 & 5 & 6 & 6 \\
\hline$\frac{e}{c 0}$ & 5 & 4 & 4 & 4 & 5 & 6 & 7 & 7 \\
\hline - & 6 & 4 & 4 & 5 & 6 & 6 & 7 & 7 \\
\hline 82 & 7 & 5 & 5 & 6 & 6 & 7 & 7 & 7 \\
\hline 8 & 8 & 5 & 5 & 6 & 7 & 7 & 7 & 7 \\
\hline
\end{tabular}

De acordo com o escore final da atividade analisada as necessidades de intervenção são divididas e classificadas nos níveis de ação:

Nível 1 - Para escores finais um ou dois onde as posturas são aceitáveis, desde que não sejam mantidas ou repetidas por longos períodos de tempo.

Nível 2 - Escores finais três ou quatro sugerem necessidade de investigação e mudanças podem ser requeridas.

Nível 3 - Os escores finais cinco ou seis indicam necessidade de investigação e mudanças em breve período de tempo.

Nível 4 - O escore sete indica necessidade de investigação e mudanças imediatas. 


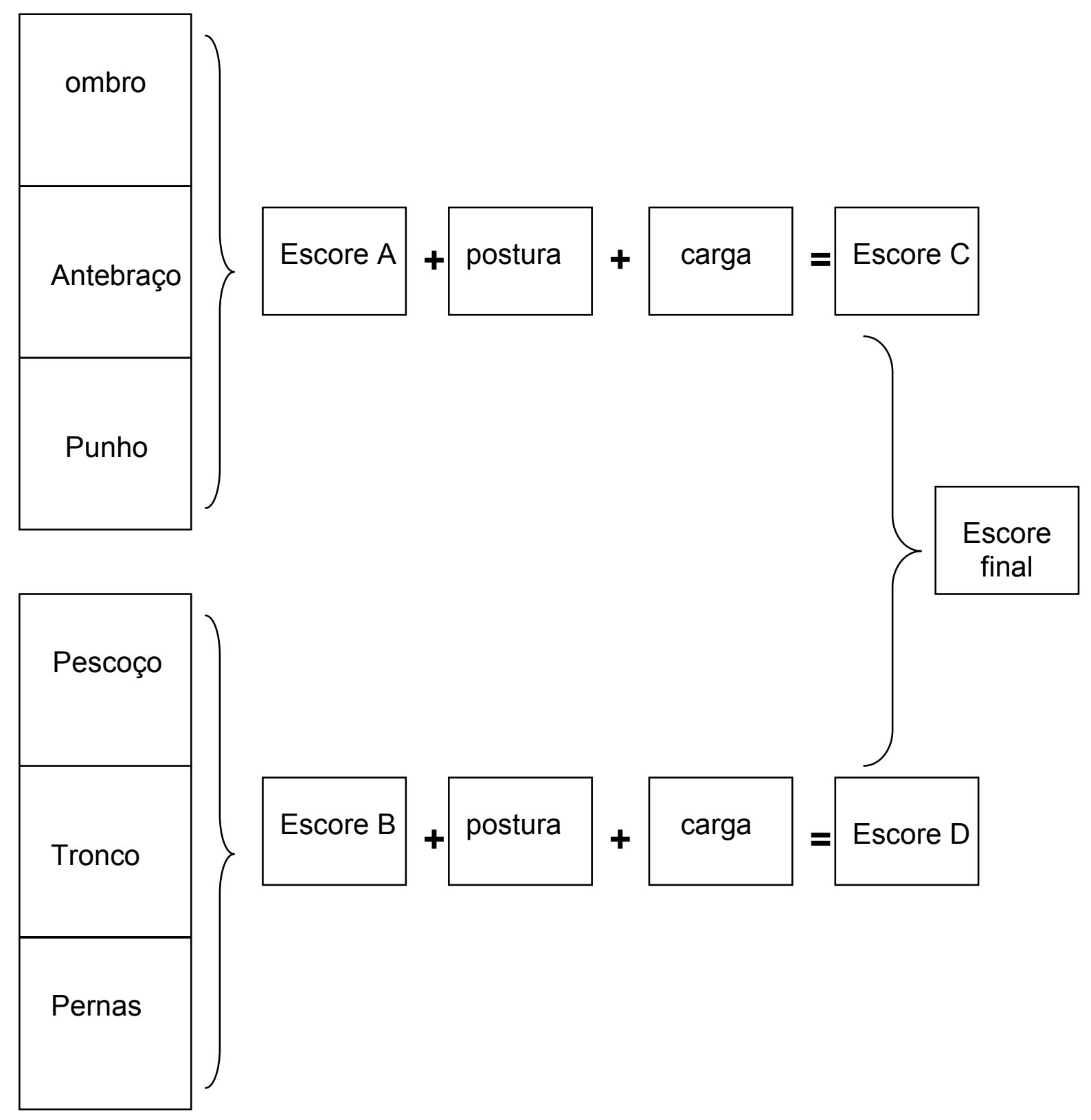

FIGURA 7 - Esquema de inserção dos escores para determinação do escore final

O método RULA foi aplicado em três fases:

1. Filmagem no plano sagital da postura assumida durante a jornada de trabalho por 30 minutos, utilizando uma câmera mini-DV JVC modelo GR DV 800U.

2. Avaliação e classificação da postura com determinação dos escores correspondentes a partir das imagens adquiridas.

3. Determinação do escore final e do nível de ação 
A filmagem se deu apenas no plano sagital, pois o membro superior, quando da posição de operação, forma uma cadeia fechada com o manete de tração o que dispensou a filmagem no plano frontal.

As posturas foram analisadas visualmente por meio do vídeo, optou-se pela divisão do intervalo total de 30 minutos, em intervalos menores de cinco minutos, onde foi observado em qual postura o maquinista mantinha-se por mais tempo, então se determinou o escore correspondente a cada intervalo.

O escore final da atividade para cada maquinista foi determinado pela moda dos escores obtidos em cada intervalo de cinco minutos.

\subsubsection{Dinâmica inversa}

As posturas dos sujeitos foram registradas, em cada posição do manete de tração (pontos $0,1,2,3,4$ ), no plano sagital por meio de uma câmera fotográfica digital, Kodak CX7300 com marcadores refletivos colocados nas seguintes proeminências anatômicas localizadas no membro superior: borda lateral do acrômio (ombro), interlinha úmero-radial (cotovelo), extremidade distal do processo estilóide da ulna (punho) e base metacarpal do dedo mínimo (FIGURA 7).

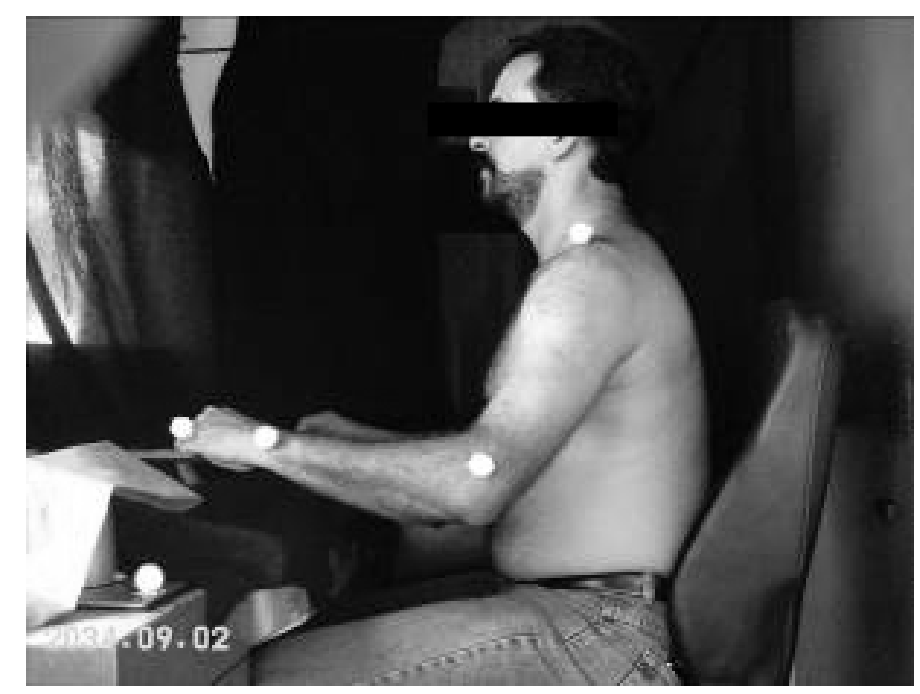

FIGURA 8 - Marcadores refletivos e respectivos pontos anatômicos

Para determinação da força empregada no manete para mantê-lo 
pressionado para baixo nos pontos de tração foi utilizada uma célula de carga modelo S5 (Alfa Instrumentos) fixada por um fio metálico inextensível à manopla do manete(FIGURA 8). A célula utilizada foi de cinco kgf com relação de 14,396 kgf por volt $(\mathrm{V})$, apresentando um erro médio de início e fundo de escala de 1,5\%. O sinal de saída da célula de carga foi coletado com uma freqüência de captura de $1000(\mathrm{~Hz})^{9}$ por um canal de um eletromiógrafo de fabricação EMG-System do Brasil, modelo EMG 800C, número de série 00189.

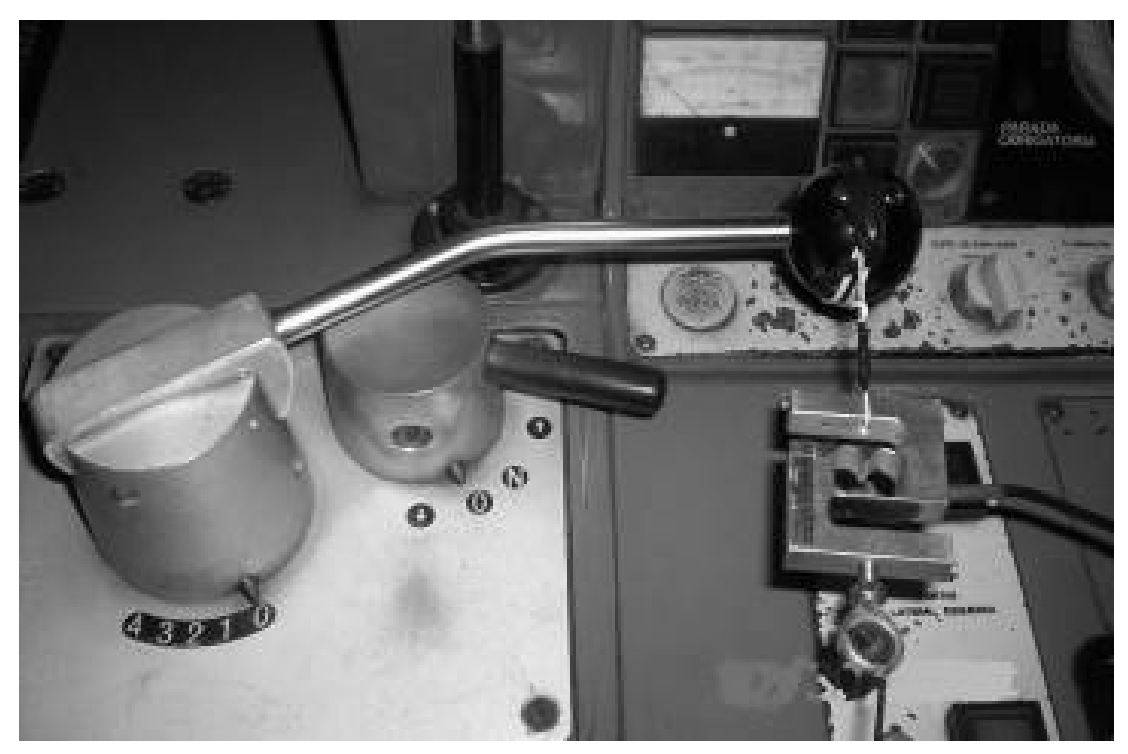

FIGURA 9 - Célula de carga fixada ao manete de tração

Após a aquisição, a fotografia foi digitalizada em quatro quadros através de um algoritmo implementado em Matlab 6.5. (Mathworks inc) com a finalidade de reduzir erros de digitalização.

Para a marcação dos pontos, reconstrução bidimensional e determinação dos ângulos segmentares do punho, cotovelo e ombro foi utilizado o software APAS (Ariel inc).

No cálculo dos torques articulares resultantes do punho, cotovelo e ombro (dinânica inversa) foi utilizando um modelo de segmento rígido bidimensional de dinâmica inversa e toda a análise foi conduzida por rotinas próprias escritas em ambiente de programação Matlab (Matlab 6.5, Mathworks).

9 Hertz $(\mathrm{Hz})$ é a unidade de frequência, expressa em termos de oscilações por segundo. 
Este modelo empregou o método de Newton-Euler baseado no membro superior como um sistema articulado por segmentos rígidos ligados pelo punho, cotovelo e ombro (diagrama de corpo livre). Para cada postura adotada no respectivo ponto de tração foi realizada uma análise estática do movimento (FIGURA 9).

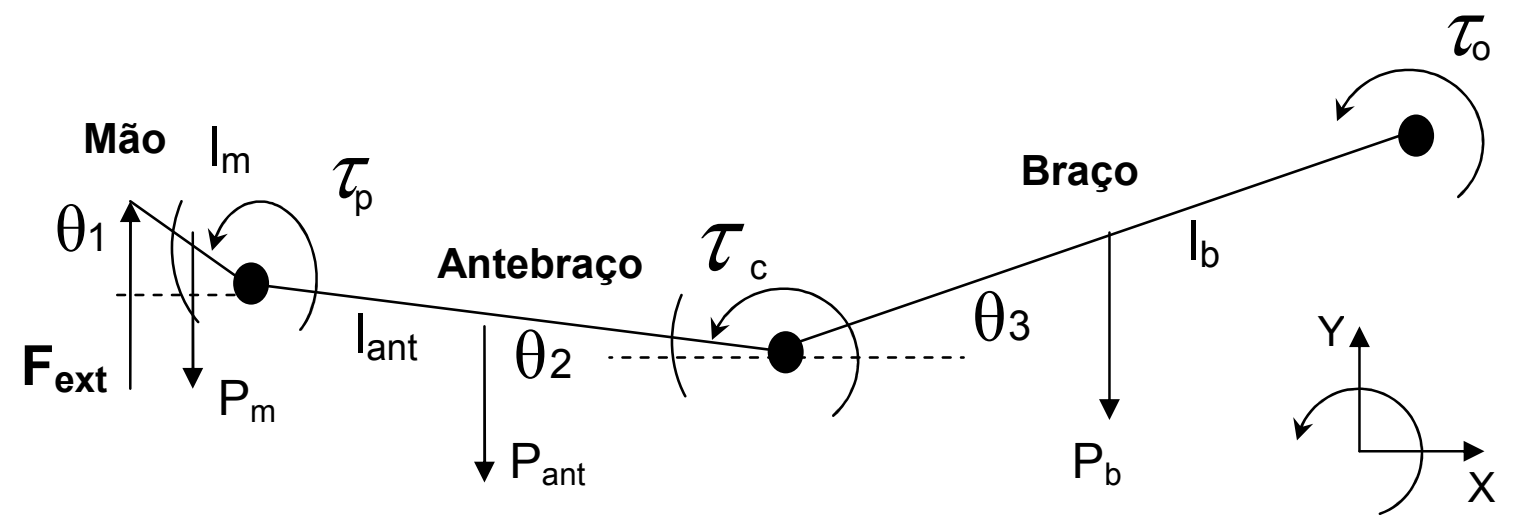

$\mathbf{F}_{\text {ext - Força externa }}$

$\theta_{1}$ - Ângulo segmentar da mão

$\theta_{2}$ - Ângulo segmentar do cotovelo

$\theta 3$ - Ângulo segmentar do ombro

lant - Comprimento do antebraço

lb - Comprimento do braço

Im - Comprimento da mão

$\tau_{\mathrm{p} \text { - Torque no punho }}$

$\tau$ c- Torque no cotovelo

$\tau$ o - Torque no ombro

$P_{m-}$ Peso da mão

$P_{\text {ant }}$ - Peso do antebraço

$P_{b}$ - Peso do braço

$$
\begin{aligned}
& \boldsymbol{\tau}_{0}=\operatorname{lb}\left|\cos \theta_{3}\right|\left(0,507 \mathrm{P}_{\mathrm{b}}+\mathrm{P}_{\mathrm{ant}}+\mathrm{P}_{\mathrm{m}}-\mathrm{F}_{\text {ext }}\right)+\operatorname{lant} \mid \cos \theta_{2}\left(0,417 \mathrm{P}_{\mathrm{ant}}+\mathrm{P}_{\mathrm{m}}-\mathrm{F}_{\text {ext }}\right) \ldots \\
& \ldots-\operatorname{Im} \mid \cos \theta_{1}\left(\mathrm{~F}_{\text {ext }}-0,515 \mathrm{P}_{\mathrm{m}}\right)
\end{aligned}
$$

FIGURA 10 - Diagrama de Corpo Livre do membro superior - Plano Sagital

A localização do centro de massa de cada segmento foi determinada como percentagem do comprimento total a partir da extremidade proximal. O peso de cada 
segmento foi estimado em função do peso corporal (ENOKA, 2000).

\subsubsection{Eletromiografia de superfície-SEMG}

Por meio de uma análise cinesiológica do movimento, estabelecemos quais os músculos seriam responsáveis pelo movimento de pressão do manete para baixo em contração isométrica com simultânea flexão e extensão do cotovelo para acionamento dos pontos de tração do manete, sendo selecionados inicialmente, os músculos: Tríceps Braquial, trapézio (longa), deltóide, peitoral, bíceps braquial e flexores do punho. Foram então determinados, em coletas piloto, os pontos motores por eletro-estimulação (FIGURA 11) e registrada a atividade elétrica muscular, onde pudemos identificar como cada um dos músculos contribuía para a realização dos movimentos durante a atividade.

Os músculos peitoral e bíceps apresentaram baixa atividade elétrica durante todas as fases dos movimentos, o que nos levou a concluir que estes não necessitavam monitoramento. Porém verificou-se, que os músculos Tríceps Braquial (longa) e flexores do punho apresentavam maior ativação durante a atividade, o que nos levou a decidir que estes seriam monitorados durante as coletas.

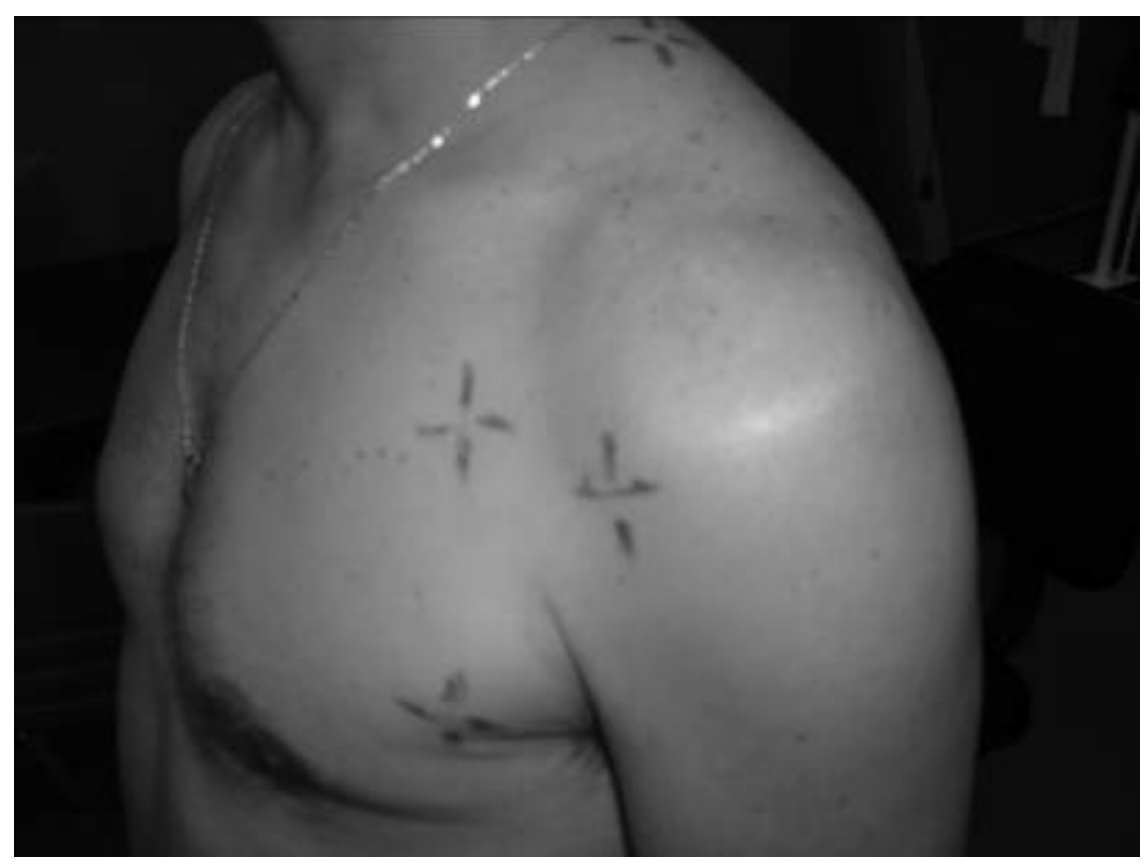

FIGURA 11 - Determinação dos pontos motores 
Eletrodos de superfície auto-adesivos (Noraxon Dual Eletrodes) $\mathrm{Ag} / \mathrm{AgCl}$ com $1 \mathrm{~cm}$ de diâmetro, espaçamento entre eletrodos de $2 \mathrm{~cm}$ de centro a centro, associados a um gel condutor, foram colocados na superfície da pele, seguindo a orientação das fibras musculares, posicionados no ventre muscular e fora do ponto motor dos músculos flexores do punho e músculo Tríceps Braquial.

Um eletrodo monopolar de referência auto adesivo (Kendal, Meditrace 200) $\mathrm{Ag} / \mathrm{AgCl}$ com $1 \mathrm{~cm}$ de diâmetro, associado a um gel condutor, foi colocado na proeminência óssea da clavícula.

Um eletromiógrafo de fabricação EMG-System do Brasil, modelo EMG $800 \mathrm{C}$, foi utilizado para aquisição do sinal eletromiográfico. O sinal foi convertido por uma placa de aquisição de 12 bits (Computer Boards, Inc, modelo PMC - DAS 16/330) com uma freqüência de aquisição de $1000 \mathrm{~Hz}$ e armazenado para posterior processamento.

Antes de realizar o registro eletromiográfico da tarefa foi solicitado ao sujeito realizar uma contração voluntária máxima isométrica (CVMI) dos músculos investigados, através de uma resistência imposta pelo avaliador para que posteriormente os dados fossem normalizados a partir dessa contração.

O registro eletromiográfico foi efetuado durante a tarefa de condução do trem em operação comercial. Foram realizadas quatro coletas do sinal em momentos distintos, correspondendo um ao início da jornada de trabalho, o segundo 30 minutos após o primeiro, outro há uma hora antes do final da jornada de trabalho e o último há 30 minutos antes do final da jornada de trabalho.

O processamento e análise do sinal EMG foram efetuados em um algoritmo escrito em ambiente de programação Matlab (Matlab 6.5, Mathworks). Os dados adquiridos foram filtrados digitalmente por um filtro Butterworth de quarta ordem, atraso de fase zero e banda de corte com freqüência de 20-400 Hz. Após a filtragem, foram removidos os dados extremos do início e do final da aquisição (uma janela de 1 segundo em cada extremidade). Para remover os ruídos de freqüência de $60 \mathrm{~Hz}$ e suas harmônicas foi utilizado um filtro Nocth.

Para análise no domínio do tempo, os dados foram normalizados através da CVMI. Posteriormente foi realizada a retificação e alisamento pela média móvel 
RMS janelada com 1 segundo de duração.

Para análise espectral foi analisado o sinal EMG bruto após a filtragem na banda $20-400 \mathrm{~Hz}$ e para tanto foi utilizada a Transformada Rápida de Fourier (FFT) e posterior estimativa das freqüências medianas do sinal.

Os valores das freqüências medianas de cada sujeito em cada instante da tarefa foram comparados utilizando-se a ferramenta estatística do teste de KrusKalWallis. O solftware utilizado para o tratamento estatístico foi o SPSS 13.0 (SPSS Inc.), mantendo o nível de significância ( $\alpha$ ) menor que 0,05.

\subsection{LIMITAÇÔES E DELIMITAÇÕES DO TRABALHO}

O presente estudo apresenta algumas limitações que, contudo não comprometem a qualidade do trabalho. Dentre estas limitações pode-se destacar:

- A análise por dinâmica inversa efetuada estaticamente e não durante a situação real da tarefa.

- A presença de vibrações durante a coleta dos dados.

- O posicionamento das câmeras em relação aos planos anatômicos quanto ao perpendicularismo.

5

\section{RESULTADOS}

O questionário QNSO foi aplicado nos 10 maquinistas, onde os mesmos registraram a presença de dor, desconforto ou dormência por regiões do corpo.

A TABELA 4 mostra o resultado da distribuição da prevalência de dor, desconforto ou dormência por regiões do corpo. 
TABELA 4 - Prevalência do sintoma de dor desconforto ou dormência por regiões do corpo nos últimos 12 meses. O escore varia entre 0 e 3(veja Material e Métodos).

\begin{tabular}{lc}
\hline Partes do corpo & $\mathbf{n ~ = ~ 1 0 ~}$ \\
\hline Pescoço & 2 \\
Ombro & 4 \\
Braço & 3 \\
Cotovelo & 0 \\
Antebraço & 2 \\
Punho / mão & 4 \\
Região dorsal & 2 \\
Região lombar & 1 \\
Quadril / membros inf. & 2 \\
\hline
\end{tabular}

Após a análise por meio da observação dos vídeos, constatou-se que todos os maquinistas adotam sempre a mesma postura durante a condução do trem. O escore final do método RULA para a atividade foi igual a quatro, correspondendo ao nível de ação dois.

Outro ponto de destaque foi a permanência na postura estática com 0 manete de tração na posição zero, durante a condução do trem. Onde se observa que o membro superior esquerdo fica mais afastado da linha média do corpo com o braço em abdução no plano escapular, contribuindo para uma maior coaptação do ombro e maior tensão dos ligamentos extra-capsulares.

A TABELA 5 apresenta o resultado dos escores finais da atividade para cada maquinista, determinados pelo método RULA e o percentual do tempo de permanência na postura estática referente ao ponto de tração zero durante uma viagem. 
TABELA 5 - Escores finais da atividade para cada maquinista com percentual do tempo de permanência na postura estática referente ao ponto de tração zero.

\begin{tabular}{cccc}
\hline Maquinista & $\begin{array}{c}\text { Tempo total } \\
\text { da viagem }\end{array}$ & $\begin{array}{c}\text { Percentual de tempo } \\
\text { na postura estática(\%) }\end{array}$ & $\begin{array}{c}\text { Escore final } \\
\text { RULA }\end{array}$ \\
\hline M1 & $28 \min 49 \mathrm{~s}$ & 51 & 4 \\
M2 & $31 \min 04 \mathrm{~s}$ & 49 & 4 \\
M2 & $24 \min 47 \mathrm{~s}$ & 61 & 4 \\
M4 & $28 \min 37 \mathrm{~s}$ & 52 & 4 \\
M5 & $27 \min 39 \mathrm{~s}$ & 39 & 4 \\
M6 & $23 \min 46 \mathrm{~s}$ & 59 & 4 \\
M7 & $30 \min 08 \mathrm{~s}$ & 51 & 4 \\
M8 & $31 \min 33 \mathrm{~s}$ & 51 & 4 \\
M9 & $30 \min 45 \mathrm{~s}$ & 52 & 4 \\
M10 & $29 \min 53 \mathrm{~s}$ & 53 & 4 \\
\hline Média & $28 \min 36 \mathrm{~s}$ & 51,8 & 4 \\
Desvio & $2 \min 17 \mathrm{~s}$ & 5,9 & 0
\end{tabular}

Os valores dos torques aplicados sobre a articulação do ombro para cada maquinista são apresentados na TABELA 6. O sinal negativo antecedente aos valores numéricos indica que a ação do torque é orientada no sentido contrário ao referencial adotado, ou seja, na tentativa de promover a flexão horizontal do braço. 
TABELA 6 - Valores dos torques no ombro para cada ponto do manete de tração em Nm.

\begin{tabular}{cccccc}
\hline Maquinista & Ponto 0 & Ponto 1 & Ponto 2 & Ponto 3 & Ponto 4 \\
\hline M1 & $-4,3$ & $-4,1$ & $-3,5$ & $-3,0$ & $-2,7$ \\
M2 & $-4,0$ & $-3,6$ & $-3,3$ & $-2,9$ & $-2,6$ \\
M3 & $-4,1$ & $-3,7$ & $-3,4$ & $-3,1$ & $-2,8$ \\
M4 & $-3,8$ & $-3,2$ & $-2,9$ & $-2,6$ & $-2,3$ \\
M5 & $-4,0$ & $-3,8$ & $-3,4$ & $-3,1$ & $-2,6$ \\
M6 & $-4,2$ & $-3,9$ & $-3,6$ & $-3,1$ & $-3,0$ \\
M7 & $-3,7$ & $-3,5$ & $-3,4$ & $-3,1$ & $-2,7$ \\
M8 & $-4,0$ & $-3,8$ & $-3,5$ & $-3,6$ & $-3,4$ \\
M9 & $-4,4$ & $-4,3$ & $-4,1$ & $-3,7$ & $-3,3$ \\
M10 & $-4,2$ & $-4,0$ & $-3,8$ & $-3,6$ & $-3,4$ \\
\hline Média & $-4,1$ & $-3,8$ & $-3,5$ & $-3,2$ & $-2,9$ \\
Desvio & 0,2 & 0,3 & 0,3 & 0,4 & 0,4 \\
\hline
\end{tabular}

A FIGURA 12 apresenta os valores médios dos torques aplicados sobre a articulação do ombro de acordo com cada ponto de tração do manete. Pode-se observar que no ponto 0 ocorre o torque máximo, promovido pela condição em que o maquinista encontra-se com o membro superior estendido e mais afastado da linha média do corpo com o braço em abdução horizontal, em contra partida ao ponto 4 onde ocorre a máxima aproximação do membro superior à linha média do corpo e o torque é mínimo. 


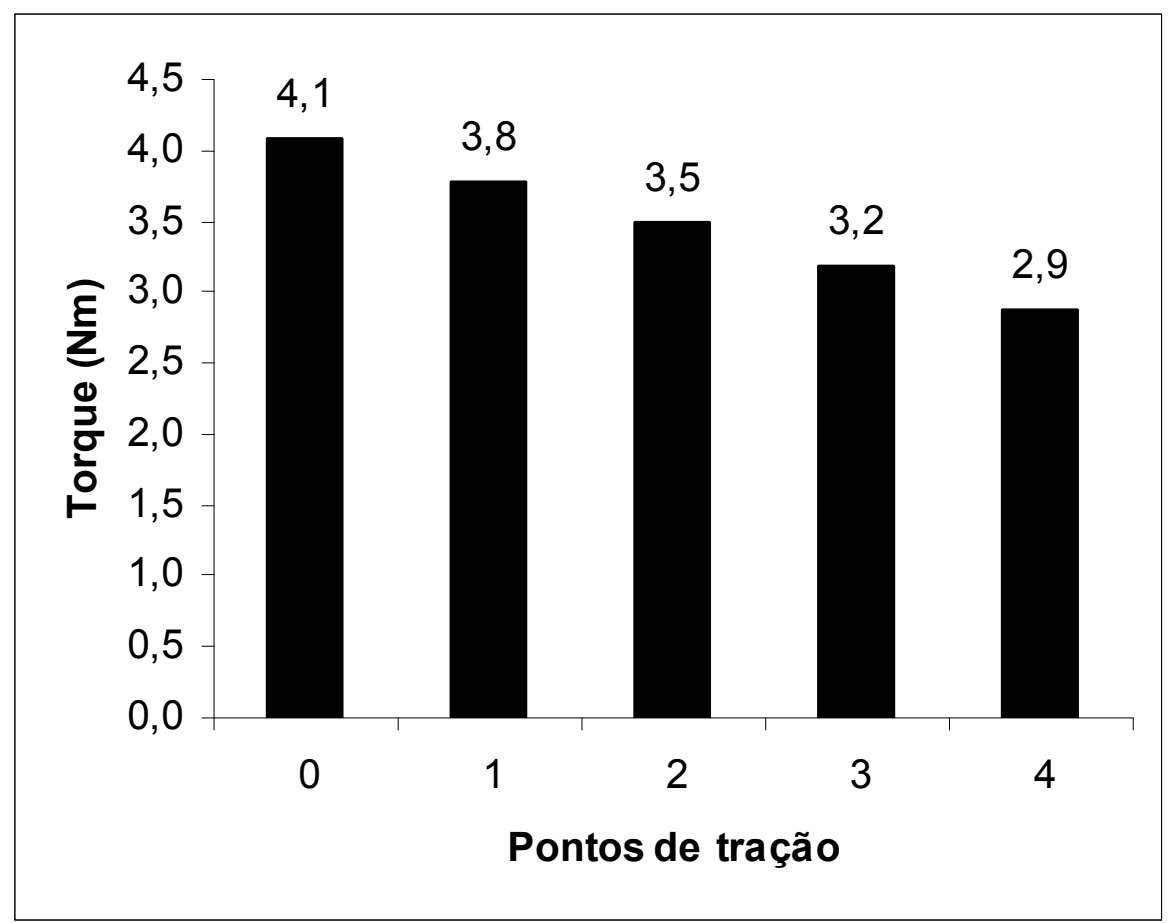

FIGURA 12 - Valores médios dos torques aplicados sobre a articulação do ombro"

Os espectros de potência do sinal eletromiográfico do músculo Tríceps Braquial de um maquinista, capturado durante a condução do trem em operação comercial, nos quatro momentos A, B, C, D distintos da coleta são apresentados na FIGURA 13. 
A

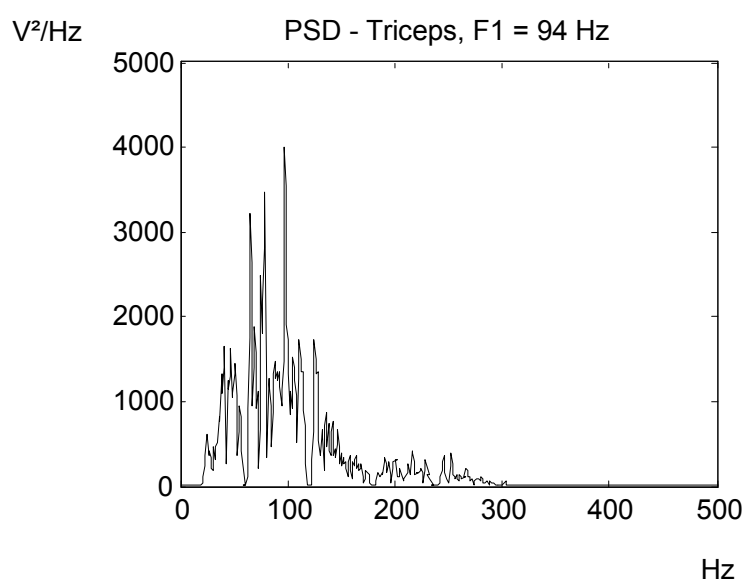

$\mathrm{V}^{2} / \mathrm{Hz}$

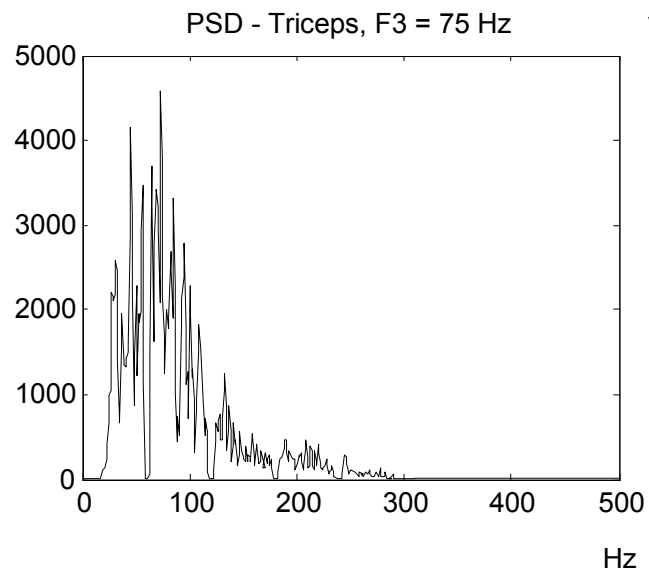

C
B

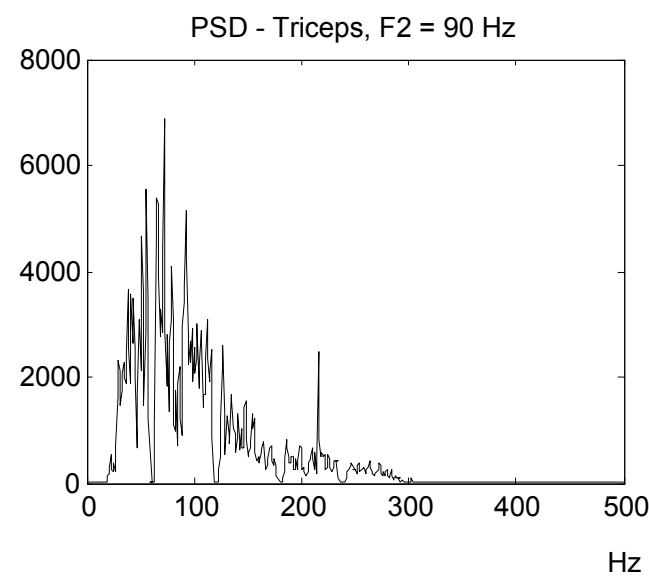

$\mathrm{V}^{2} / \mathrm{Hz}$

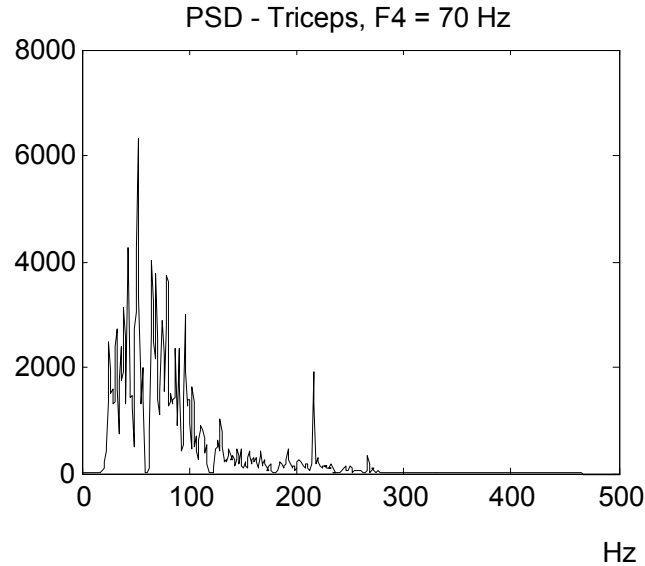

D

FIGURA 13 - Espectros de potência do sinal eletromiográfico do músculo Tríceps Braquial

As TABELAS 7 e 8 mostram respectivamente os valores das freqüências medianas dos músculos Tríceps Braquial e flexores do punho de todos os sujeitos, nos quatro momentos distintos da coleta. Para a comparação entre as freqüências foi aplicado o teste não paramétrico de Kruskal-Wallis $(p=0,437)$.. 
TABELA 7 - Freqüências medianas do músculo Tríceps Braquial

\begin{tabular}{ccccc}
\hline \multicolumn{5}{c}{ Freqüências medianas (Hz) } \\
\hline Maquinista & F1 & F2 & F3 & F4 \\
\hline M1 & 146 & 127 & 109 & 85 \\
M2 & 52 & 57 & 56 & 64 \\
M3 & 53 & 117 & 105 & 86 \\
M4 & 157 & 84 & 141 & 132 \\
M5 & 81 & 80 & 71 & 66 \\
M6 & 87 & 110 & 93 & 97 \\
M7 & 111 & 117 & 83 & 97 \\
M8 & 115 & 86 & 75 & 72 \\
M9 & 94 & 90 & 75 & 70 \\
M10 & 85 & 102 & 105 & 110 \\
\hline Média & 98,1 & 97,0 & 91,3 & 87,9 \\
Desvio & 34,9 & 21,4 & 24,5 & 21,7
\end{tabular}

TABELA 8 - Freqüências medianas dos músculos flexores do punho

\begin{tabular}{ccccc}
\hline \multicolumn{5}{c}{ Freqüências medianas (Hz) } \\
\hline Maquinista & F1 & F2 & F3 & F4 \\
\hline M1 & 134 & 99 & 104 & 143 \\
M2 & 82 & 93 & 97 & 88 \\
M3 & 101 & 104 & 108 & 99 \\
M4 & 103 & 97 & 101 & 102 \\
M5 & 103 & 100 & 91 & 111 \\
M6 & 95 & 134 & 112 & 95 \\
M7 & 115 & 127 & 103 & 162 \\
M8 & 104 & 105 & 86 & 109 \\
M9 & 102 & 109 & 102 & 101 \\
M10 & 100 & 96 & 95 & 91 \\
Media & 103,9 & 106,4 & 99,9 & 110,1 \\
Desvio & 13,4 & 13,6 & 7,8 & 23,9 \\
\hline
\end{tabular}


Os gráficos das FIGURAS 14 e 15 representam boxplots com os valores das freqüências medianas do músculo Tríceps Braquial de todos os sujeitos, nos quatro momentos distintos da coleta

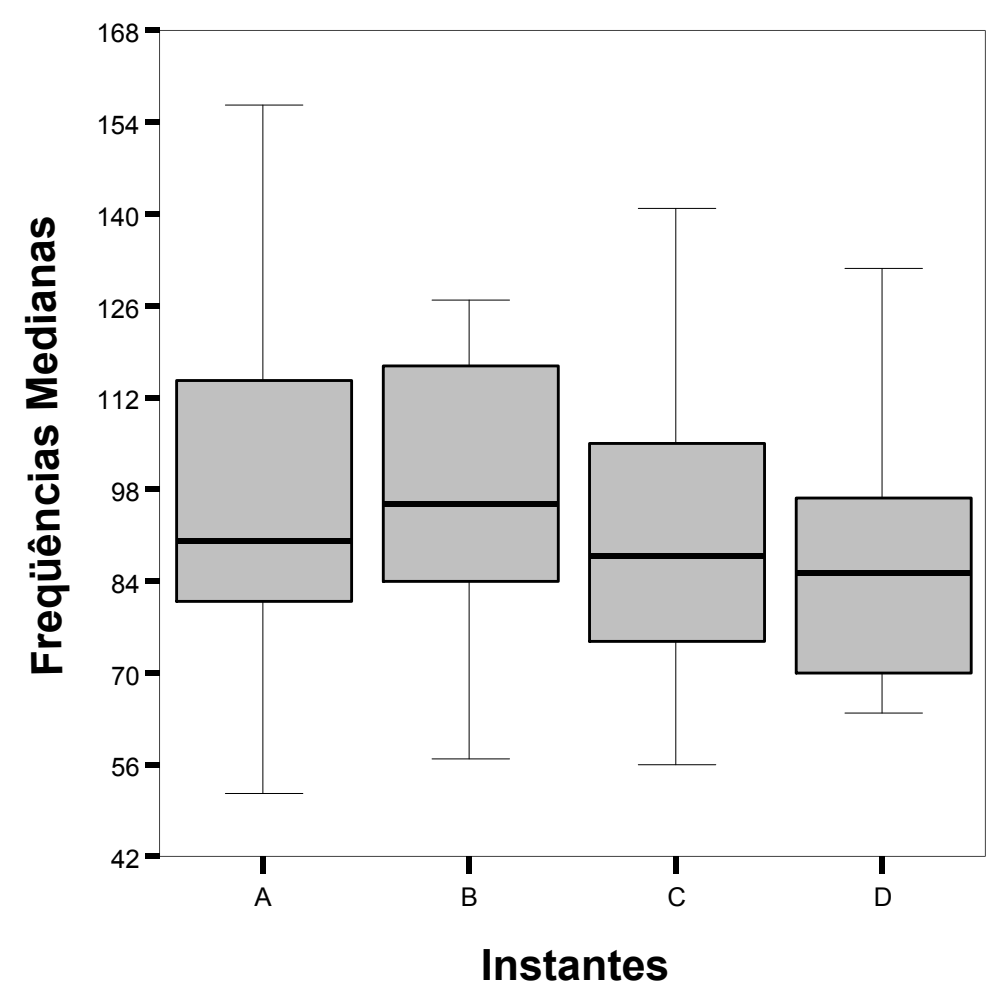

FIGURA 14 - Boxplot das freqüências medianas do músculo Tríceps Braquial 


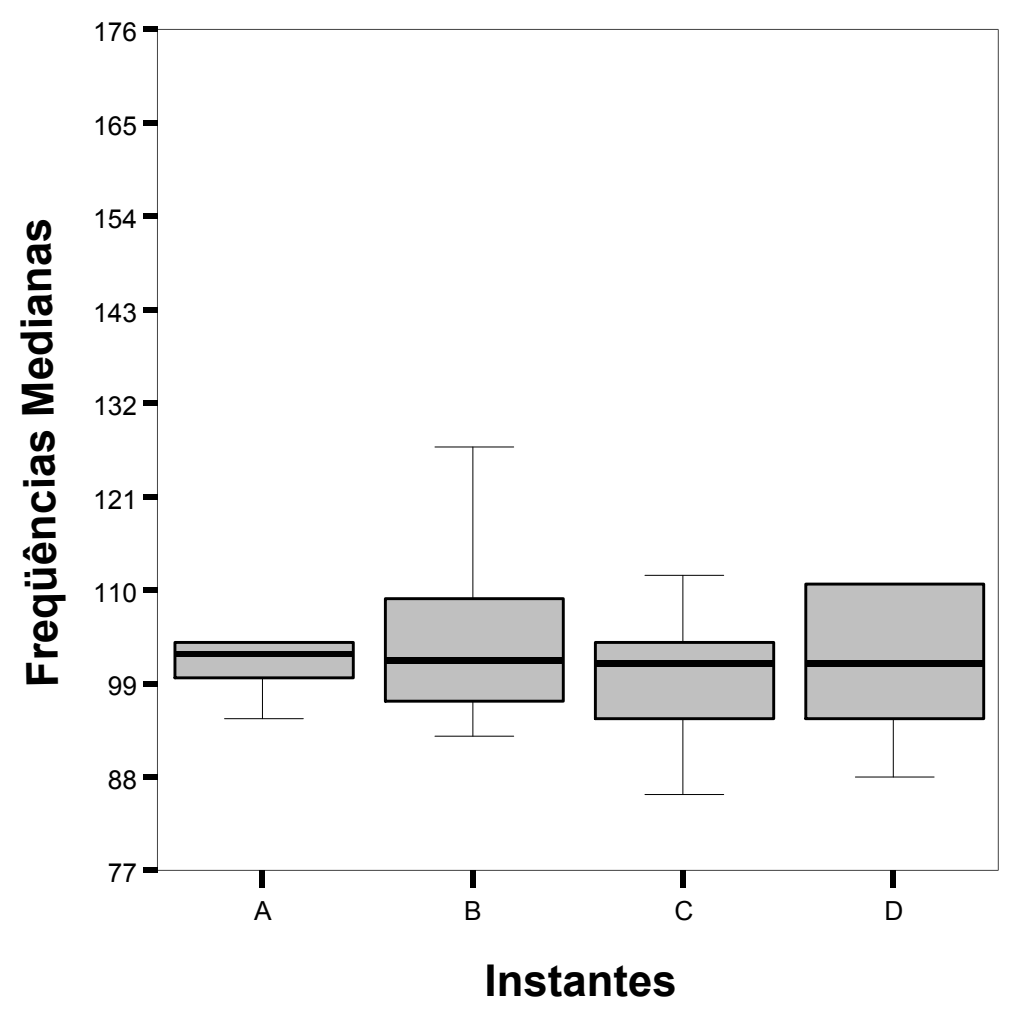

FIGURA 15 - Boxplot das freqüências medianas dos músculos flexores do punho

O comportamento do sinal eletromiográfico normalizado pela CVMI em função do tempo é apresentado na FIGURA 16. 

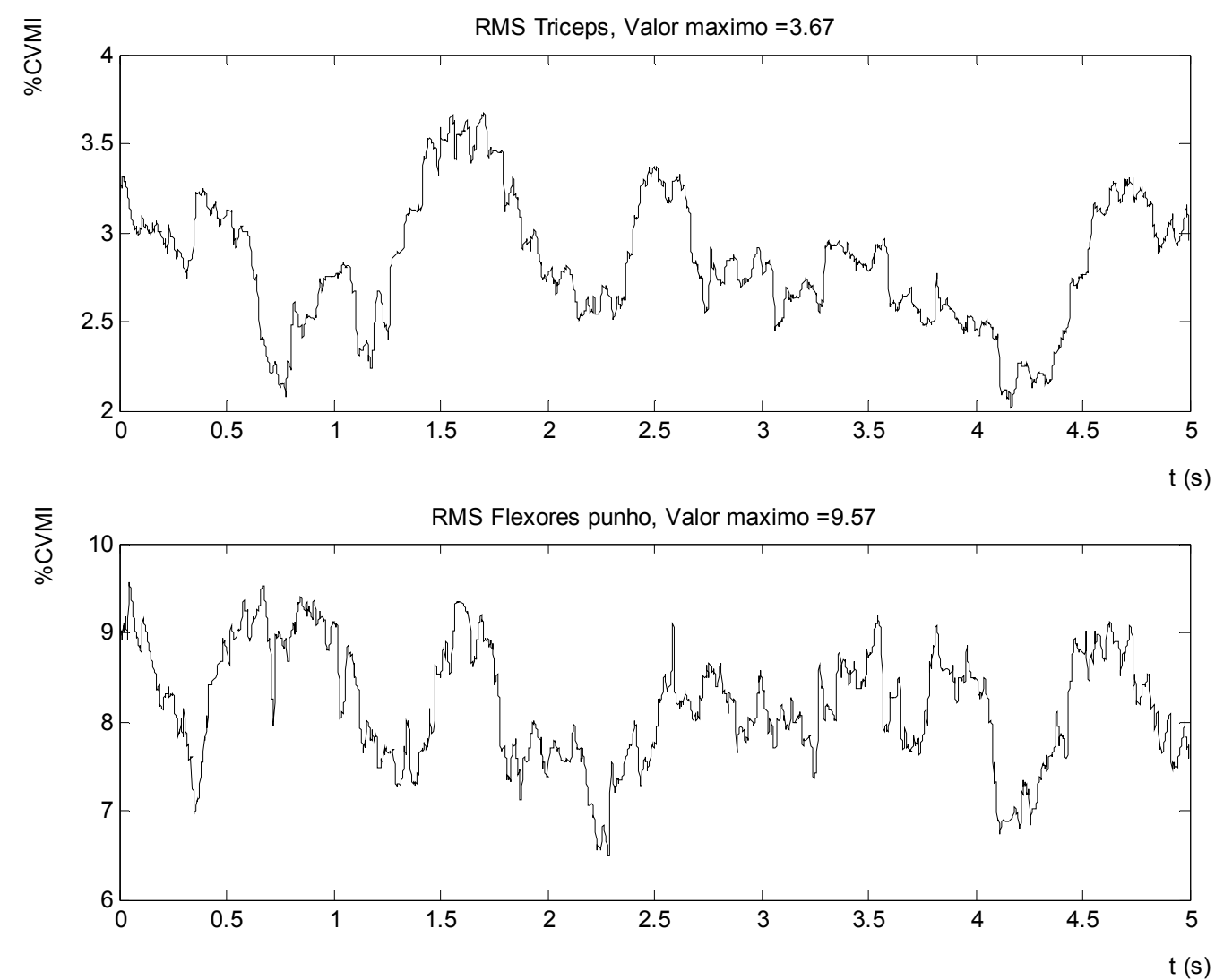

FIGURA 16 - Representação gráfica do RMS para os músculos Tríceps Braquial e flexeros do punho normalizado pela CVMI

As TABELAS 9 e 10 mostram os valores máximos do RMS normalizado pela CVMI para os músculos Tríceps Braquial e flexores do punho para os quatro momentos distintos da coleta. 
TABELA 9 - Valores máximos do RMS normalizado pela CVMI para o músculo Tríceps Braquial

\begin{tabular}{ccccc}
\hline Maquinista & \multicolumn{4}{c}{ RMS - Tríceps Braquial (\%CVMI) } \\
\hline M1 & 27,2 & 9,6 & 15,2 & 45,3 \\
M2 & 5,8 & 3,8 & 4,3 & 3,2 \\
M3 & 10,7 & 5,2 & 3,4 & 2,9 \\
M4 & 5,9 & 3,8 & 6,1 & 7,1 \\
M5 & 11,7 & 6,9 & 5,1 & 17,6 \\
M6 & 53,6 & 25,1 & 37,5 & 26,7 \\
M7 & 6,7 & 4,1 & 29,2 & 7,9 \\
M8 & 13,2 & 16,9 & 30,9 & 14,9 \\
M9 & 3,5 & 4,5 & 3,8 & 3,7 \\
M10 & 2,5 & 3,8 & 4,0 & 6,9 \\
\hline Média & 14,1 & 8,4 & 13,9 & 13,6 \\
Desvio & 15,6 & 7,2 & 13,4 & 13,5 \\
\hline
\end{tabular}

TABELA 10 - Valores máximos do RMS normalizado pela CVMI para os músculos flexores do punho

\begin{tabular}{ccccc}
\hline Maquinista & \multicolumn{4}{c}{ RMS - flexores do punho (\%CVMI) } \\
\hline M1 & 51,6 & 46,9 & 81,8 & 94,3 \\
M2 & 16,2 & 10,0 & 11,0 & 3,6 \\
M3 & 13,7 & 12,6 & 11,3 & 3,8 \\
M4 & 39,7 & 22,5 & 33,9 & 49,6 \\
M5 & 33,4 & 14,9 & 15,2 & 9,7 \\
M6 & 8,3 & 4,8 & 6,7 & 9,6 \\
M7 & 9,0 & 7,6 & 32,8 & 55,4 \\
M8 & 20,2 & 15,0 & 10,4 & 19,7 \\
M9 & 11,1 & 28,5 & 16,4 & 9,6 \\
M10 & 12,5 & 19,4 & 11,7 & 13,9 \\
\hline Média & 21,6 & 18,2 & 23,1 & 26,9 \\
Desvio & 14,9 & 12,3 & 22,6 & 29,9 \\
\hline
\end{tabular}


Este estudo teve como objetivo estimar a carga mecânica e a atividade muscular no membro superior esquerdo de maquinistas condutores de trens metropolitanos durante o trabalho. Especificamente, o estudo procurou estimar a carga mecânica sobre a articulação do ombro, avaliar a atividade muscular dos músculos tríceps e flexores do punho e verificar a ocorrência de fadiga muscular durante a realização da tarefa, para isto foram investigados o fator de risco relacionado a enfermidades dos membros superiores por meio da determinação do escore da atividade, o torque sobre a articulação do ombro e a freqüência mediana do sinal eletromiográfico.

Os resultados mostram que as regiões do corpo mais citadas com sintomas de dor são o ombro e o punho, o método RULA indica para atividade um escore final quatro, o torque máximo calculado sobre a articulação do ombro apresenta valor médio de $-4,1 \mathrm{Nm}$ e não foi observada a instauração de fadiga muscular

As maiores incidências de desconforto aparecem no ombro e punho, ambas quatro vezes, o que ratifica o grande número de queixas por parte dos maquinistas.

Observamos também, neste estudo, que os maquinistas apresentam praticamente o mesmo procedimento e seqüência de movimentos para a execução da atividade de condução, as pequenas diferenças observadas são decorrentes da individualidade de cada sujeito. Outro fato relevante observado é a permanência, por cerca de mais de $50 \%$ de todo tempo total da jornada de trabalho, na postura com o manete de tração na posição zero durante a condução do trem o que sugere predisposição para lesões por traumas cumulativos por ser, de acordo com a literatura, uma atividade repetitiva. COUTO e MORAES (2003) consideram como tarefa repetitiva a atividade que apresenta um ciclo de trabalho menor que 30 segundos, ou o ciclo maior que 30 segundos com mais de $50 \%$ do tempo ocupado com apenas um tipo de movimento.

\subsection{Escore da atividade}


O método RULA foi desenvolvido para analisar a exposição de sobrecarga musculoesquelética a metodologia conta com a observação por meio de filmagem não utilizando meios tecnológicos auxiliares como programas de avaliação. A análise das imagens com congelamento facilita muito a identificação, com maior precisão das posturas assumidas que é à base do método para a determinação do escore.

Neste estudo foram analisados 10 sujeitos, onde se identificou que a postura assumida é exigida devido ao posicionamento e layout da cabina, obrigando o maquinista a manter o membro superior esquerdo afastado do eixo do corpo na maior parte do tempo, e que se mantida por períodos prolongados esta postura é potencialmente geradora de sobrecarga musculoesquelética, e pode estar associada ao aparecimento de DORT.

A aplicação do método neste estudo foi fundamental, pois se determinou um escore específico para a atividade como proposto por MCATAMNEY e CORLETT (1993), sendo esse escore final igual a quatro, conforme TABELA 6, indicando que a atividade apresenta nível de ação dois que sugere necessidade de investigação e mudanças podem ser requeridas. Estas mudanças devem procurar diminuir a abdução do braço de modo que este segmento corporal permaneça em uma posição confortável, ou seja, mais próximo da linha média do corpo e também a diminuição ou retirada da tensão da mola do manete.

Estudos como o de SEN e GANGULI (1982) e STEVENSON et al.(2000) concluíram que a falta de avaliações biomecânicas e considerações antropométricas no projeto de cabinas de locomotivas interferem significativamente nas condições de trabalho corroborando com estas observações.

Os instrumentos e equipamentos são aspectos determinantes das condições, espaço e dimensões de planos de trabalho, como também outros fatores fundamentais determinam as posturas laborais, principalmente as exigências visuais (movimentos da cabeça), exigências de precisão de movimentos (movimentos diante e perto do eixo corporal), e exigências de força (alavancas corporais) (LAVILLE, 1977).

\subsection{Torque articular}


Com a aplicação da dinâmica inversa e utilizando-se os valores das medidas antropométricas apresentados na TABELA 5, estimou-se um torque articular médio sobre o ombro de $-4,1 \pm 0,2 \mathrm{Nm}$ na posição em que o manete de tração está no ponto 0 , este valor corresponde a uma força de cerca de 4,1 $\mathrm{N}$ aplicada a uma distância de um metro desta articulação, ou seja, representativamente semelhante a segurar um objeto de aproximadamente $0,6 \mathrm{~kg}$ com o braço em flexão horizontal e cotovelo estendido, considerando que o comprimento médio do membro superior de um adulto é de $70 \mathrm{~cm}$. Conforme o sistema de referencia adotado, este torque possui sinal negativo, o que significa que ele atua sobre a articulação do ombro no sentido da flexão.

Com o manete na posição 0, o maquinista assume uma postura onde o braço é abduzido no plano escapular e ao percorrer os pontos de tração este segmento corporal vai se colocando mais no plano frontal, aproximando a cabeça do úmero ao arco coracoacromial e reduzindo o espaço subacromial.

Para NEUMANN (2006), a compressão contínua da cabeça do úmero contra os conteúdos do espaço subacromial leva à "síndrome do impacto crônico" caracterizada pela incapacidade de abduzir o ombro de uma maneira natural e indolor. Esta condição ocorre tipicamente em atletas, trabalhadores e pessoas sedentárias.

Muitos fatores expõem as pessoas à síndrome do impacto, entre eles a má postura torácica, degeneração dos músculos do manguito rotador, tensões no interior da cápsula articular, entre outros.

NEUMANN (2006) também afirma que independente das causas, sempre ocorre impacto entre as estruturas articulares do ombro, fazendo com que o tendão do músculo supra-espinhal e a bolsa subacromial sofram traumatismos. A cabeça longa do músculo bíceps braquial e a parte superior da cápsula articular também podem sofrer impactos e ficar traumatizadas.

MURRAY e JOHNSON (2004) determinaram os torques sobre a articulação do ombro para 10 atividades de vida diária, escolhidas de acordo com a relevância da ação real dos membros superiores e particularmente a carga sobre esta articulação. Os valores mais altos, aproximadamente $14 \mathrm{Nm}$ em torno do eixo de 
flexão, foram encontrados para tarefas de levantar objetos com peso máximo de $5 \mathrm{~N}$ acima da altura do ombro e da cabeça.

Corroborando os achados anteriores, BJÖRKSTÉN e JONSSON (1977) apud MCATAMNEY e CORLETT (1993), mostraram que força muscular estática não deve exceder 5 a $6 \%$ da CVM por mais de 1 hora. Observa-se neste estudo, que a maior parte dos sujeitos mantém a força muscular do Tríceps Braquial e flexores do punho acima dos limites estabelecidos. Como também, ocorrem durante a atividade de condução, picos de força relativamente altos, conforme mostram as TABELAS 10 e 11, esses picos embora aconteçam em intervalos de tempo pequenos, cerca de 0,5 segundo, podem para provocar lesões, pois estão presentes durante toda jornada de trabalho (mais de seis horas diárias) contribuindo para elevação do torque articular.

As lesões por traumas cumulativos nos membros superiores são decorrentes da interação de quatro fatores biomecânicos principais: força, posturas incorretas, repetitividade, compressão mecânica. O aumento da intensidade de um dos fatores, a partir de um determinado ponto crítico proporcionará um aumento gradativo na incidência das lesões, se houver um segundo fator, mais fácil será a ocorrência, e assim por diante (COUTO \& MORAES, 2003)

Considerando a natureza da atividade estudada e os resultados encontrados referentes aos torques, sobre a articulação do ombro, e observando as referencias na literatura, pode-se sugerir que esta prática laboral contribua para o aparecimento de DORT.

\subsection{Freqüência mediana}

A análise espectral do sinal do EMG apresenta-se como uma ferramenta sensível às alterações musculares diante da fadiga por apresentar um comportamento de freqüência bem definido, enquanto na análise temporal por meio do RMS pode-se observar grande variabilidade no sinal eletromiográfico. Por isso não se pode definir um padrão para o comportamento do músculo através dessa análise, tornando difícil sua utilização como indicativo de fadiga muscular. Para

\footnotetext{
${ }^{10}$ Bjiirksten, $\mathbf{M}$ and Jonsson, B 'Endurance limit of force in long-term intermittent static contraction' Stand J WorkEnviron Health, Vol 3 (1977) pp 23-27
} 
DIMITROVA e DIMITROV (2003), o estudo da amplitude do sinal eletromiográfico não é um a ferramenta confiável para a detecção da fadiga muscular.

De acordo com a TABELA 8, podemos notar que quatro sujeitos apresentaram uma diminuição da freqüência mediana do sinal eletromiográfico, durante a realização da tarefa, o que poderia sugerir que estes sujeitos fadigaram durante a jornada de trabalho, todavia observando as FIGURAS 14 e 15, os boxplots apresentam uma grande interseção sendo difícil avaliar a existência de diferença real entre as freqüências.

A aplicação do teste de Kruskal-Wallis resultou $p=0,437$ onde se conclui que não há evidências suficiente para se considerar diferenças entre as freqüências, o que pode ser conseqüência do tamanho da amostra, sendo necessário outros estudos para se investigar a presença de fadiga muscular durante a realização desta atividade laboral.

Portanto, diante das informações referentes a este experimento, não foi possível observar a instauração de fadiga muscular no membro superior esquerdo dos sujeitos estudados.

\section{$7 \quad$ CONCLUSÕES}

Com base nos resultados encontrados neste experimento, conclui-se que a carga mecânica sobre o membro superior esquerdo dos maquinistas não é excessiva em termos da amplitude da carga. Todavia a atividade laboral estudada apresenta um escore final que sugere mais investigações e mudanças podem ser requeridas, pois é verificado que a postura adotada gera desconforto.

O torque articular médio atuante sobre a articulação do ombro atinge seu valor máximo com o manete de tração na posição 0 , onde o maquinista assume a postura mais inadequada, ou seja, o braço esquerdo em abdução no plano escapular com o cotovelo estendido. Este torque é baixo, porém é aplicado por cerca da metade da jornada de trabalho e potencializado pelo aparecimento de picos de força muscular o que pode gerar lesões que, com o decorrer do tempo, levam ao aparecimento de distúrbios osteomusculares. 
A instauração de fadiga sobre os músculos Tríceps Braquial e flexores do punho não foi observada, isto se deve provavelmente à característica da tarefa que apresenta intervalos de tempo, entre viagens, suficiente para a recuperação da musculatura.

Contudo, estudos futuros são recomendados para desenvolvimento de cabinas de trens metropolitanos com layout ergonômico e posicionamento de instrumentos que possibilite uma postura mais adequada dos operadores. Mais especificamente, nossos resultados permitem recomendar que fosse modificado o manete de tração com diminuição da força para mantê-lo pressionado e instalado mais próximo da linha média do corpo, reduzindo o ângulo de abdução do braço. 


\section{REFERËNCIAS}

AUSTIN, A.DRUMMOND, P. D. Work problems associated with suburban train driving. Applied Ergonomics, Nottingham, v.17, n.2, p.111-6. 1986.

ABRAHÃO, J. I.PINHO, D. L. M. As transformações do trabalho e desafios teóricosmetodológicos da Ergonomia. Estudos de Psicologia, Campinas, v.7, p.45-52. 2002.

ANTONIO, R. L. ESTUDO ERGONÔMICO DOS RISCOS DE LER/DORT EM LINHA DE MONTAGEM: aplicando o método occupational repetitive actions (OCRA) na análise ergonômica do trabalho (AET). 2003. 114 f. (DISSERTAÇÃO MESTRADO). Engenharia de Produção, Universidade Federal de Santa Catarina, Florianópolis.

ARAÚJO, M. A.PAULA, M. V. Q. D. LER/DORT: UM GRAVE PROBLEMA DE SAÚDE PÚBLICA QUE ACOMETE OS CIRURGIÕES-DENTISTAS. Revista de APS, Juiz de Fora, v.6, n.2. 2003.

BUCHANAN, T. S., LLOYD, D. G., MANAL, K.BESIER, T. F. Estimation of Muscle Forces and Joint Moments Using a Forward-Inverse Dynamics Model. Medicine \& Science in Sport \& exercise, Madison, p.1911-1916. 2005.

CHAFFIN, D. B., ANDERSSON, G. B. J.MARTIN, B. J. Occupational Biomechanics. 3 ed. Michigan: Wiley-Interscience 1997

CÔTÉ, J. N., RAYMOND, D., MATHIEU, P. A., FELDMAN, A. G.LEVIN, M. F. Differences in multi-joint kinematic patterns of repetitive hammering in healthy, fatigued and shoulder-injured individuals. Clinical Biomechanics (Bristol, Avon), Huddersfield, UK, v.20, n.6, p.581-90. 2005.

COUTO, H. A.MORAES, L. F. R. Novas perspectivas na prevenção dos distúrbios dolorosos dos membros superiores: o entendimento dos fatores de organização do trabalho e psicossociais envolvidos em sua origem. Revista Brasileira de Medicina do Trabalho, Belo Horizonte, v.1, n.1, p.43-58. 2003.

DE LUCA, C. J. The Use of Electromyography in Biomechanics. Journal of Applies Biomechanics, Champain, v.13, p.135-163. 1997.

DIMITROVA, N. A.DIMITROV, G. V. Interpretation of EMG changes with fatigue: facts, pitfalls, and fallacies. Journal of Electromyography and Kinesiology, Amsterdam, v.13, n.1, p.13 - 36. 2003.

DUL, J.WEERDMEERSTER, B. Ergonomia Prática. São Paulo: Edgard Blücher. 1995

ENOKA, R. M. Bases Neuromecânicas da Cinesiologia. São Paulo: Manole. 2000 
FERREIRA, M. C. O Sujeito Forja o Ambiente, o Ambiente "Forja" o Sujeito: Interrelação Indivíduo-Ambiente em Ergonomia da Atividade. Brasília: Laboratório de Ergonomia, Dep. de Psicologia Social e do Trabalho PST, Universidade de Brasília, 2002.

FORSMAN, M., HANSSON, G. A., MEDBO, L., ASTERLAND, P.ENGSTROM, T. A method for evaluation of manual work using synchronised video recordings and physiological measurements. Applied Ergonomics, Nottingham, v.33, n.6, p.533-40. 2002.

GUEDES, D. P.GUEDES, J. E. R. P. Manual prático para avaliação em educação física. São Paulo: Manole. 2005

HIRATA, R. P. Análise biomecânica do agachamento. 2005. f. (DISSERTAÇÃO MESTRADO). Biodinâmica do Movimento Humano, Universidade de São Paulo, São Paulo.

HOSTENS, I.RAMON, H. Assessment of muscle fatigue in low level monotonous task performance during car driving. Journal Electromyography and Kinesiology, Amsterdam, v.15, n.3, p.266-74. 2005.

HWANG, K. S. Influência das Ondas de Choque Induzidas pelo Contato Inicial e da Atividade Muscular na Transição Caminhada-Corrida 2006. f. Engenharia Biomédica, Universidade Federal do Rio de Janeiro, Rio deJaneiro.

KAPANDJI, A. I. Fisiologia Articular, v.1. 5a. Rio de Janeiro: Guanabara Koogan. 2000

KOHN, A. F.MEZZARANE, R. A. Métodos em Eletromiografia. In: D. F. VenturaK. Sameshima (Ed.). Métodos em Neurociências e Comportamento. São Paulo, v.I, 2005. Métodos em Eletromiografia

KROEMER, K. H. E. Cumulative traumas disorders, their recognition and ergonimics measures to avoid them. Applied Ergonomics, Nottingan, v.20, n.4, p.274-280. 1989.

LAVILLE, A. Ergonomia. São Paulo: EPU, Editora da Universidade de São Paulo. 1977

LIDA, I. Ergonomia: projeto e produção. $2^{\mathrm{a}}$ ed rev. e ampl. São paulo: Edgard Blücher. 2005

MALCHAIRE, J. B., COCK, N. A., PIETTE, A., LEAO, R. D., LARA, M.AMARAL, F. Relationship between work constraints and the development of musculoskeletal disorders of the wrist: A prospective study International Journal of Industrial Ergonomics, Clemson, v.19, n.6, p.471-482. 1997. 
MANSFIELD, N. J.MARSHALL, J. M. Symptoms of musculoskeletal disorders in stage rally drivers and co-drivers. British Journal of Sports Medicine, London, v.35, n.5, p.314-20. 2001.

MARCHETTI, P. H. Investigação sobre o Controle Neuromotor do Músculo Reto Abdominal. 2004. 90 f. (DISSERTAÇÃO MESTRADO). Biodinâmica do Movimento Humano, Universidade de São Paulo, São Paulo.

MASSACCESI, M., PAGNOTTA, A., SOCCETTI, A., MASALI, M., MASIERO, C.GRECO, F. Investigation of work-related disorders in truck drivers using RULA method. Applied Ergonomics, Nottingham, v.34, n.4, p.303-7. 2003.

MCATAMNEY, L.CORLETT, E. N. RULA: a survey method for the investigation of work-related upper limb disorders. Applied Ergonomics, Nottingham, v.24, n.2, p.9199. 1993.

MPAS. Instrução Normativa INSS/DC Nº 98

Brasilia DOU 10/12/2003 2003.

- Anuário Estatístico da Previdência Social. Disponível em: http:// www.mpas.gov.br/aeps2004/docs 2006.

MURRAY, I. A.JOHNSON, G. R. A study of the external forces and moments at the shoulder and elbow while performing every day tasks. Clin Biomech (Bristol, Avon), Jul, v.19, n.6, p.586-94. 2004.

NEUMANN, D. A. Cinesiologia do aparelho musculoesquelético: fundamentos para a reabilitação física. Rio de Janeiro Guanabara Koogan. 2006

$\mathrm{NIOSH}$. National Institute for Occupational Safety and Health Musculoskeletal Disorders and Workplace Factors

Surface Electromyography Procedures Manual for use in the Industrial Setting. 1990. f., U.S. Department of Health and Human Services, Morgantown.

. National Institute for Occupational Safety and Health Musculoskeletal Disorders and Workplace Factors

A Critical Review of Epidemiologic Evidence for Work-Related Musculoskeletal Disorders of the Neck, Upper Extremity, and Low Back. 1997. f., U.S. Department of Health and Human Services, Cincinnati.

OLIVEIRA, L., MORAES, M. F., OLIVEIRA, P.ABECASIS, P. A train driver with painful legs. Lancet, Oxfort, v.353, n.9169, p.2034. 1999.

PEREIRA, V. C. G. A Contribuição da Ergonomia no Registro e Prevenção das LER/DORT em Centrais de Atendimento: um estudo de caso. 2001. f. (DISSERTAÇÃO MESTRADO). UFSC, Florianópolis. 
PINZKE, S., STÅL, M.HANSSON, G.-Å. PHYSICAL WORKLOAD ON UPPER EXTREMITIES IN VARIOUS OPERATIONS DURING MACHINE MILKING. Annals of Agricultural and Environmental Medicine, v.8, p.63-70. 2001.

PRZYSIEZNY, W. L. Distúrbios Ostemusculares Relacionados ao Trabalho: um enfoque ergonômico. Ensaios de Ergonomia - Revista Virtual de Ergonomia. Florianópolis 2000.

PUTZ-ANDERSON, V. Cumulative trauma disorders: A manual for musculoskeletal diseases of the upper limbs. London: Taylor \& Francis. 1988

RASIA, D. Quando a Dor é do Dentista! Custo Humano do Trabalho de Endodontistas e Indicadores de Dort. 2004. f. (DISSERTAÇÃO MESTRADO). Departamento de Psicologia Social e do Trabalho, Unb, Brasília.

REID, A., PINDER, A.MONNINGTON, S. Musculoskeletal problems in bricklayers,carpenters and plasterers: Literature review and results of site visits. Health and Safety Laboratory (HSL). Derbyshire, UK. 2001

RIBEIRO, H. P. Lesões por Esforços Repetitivos (LER): uma doença emblemática. Caderno de Saúde Pública, São Paulo, v.13, n.2, p.85-93. 1997.

SEN, R. N.GANGULI, A. K. Preliminary investigations into the loco-man factor on the Indian railways. Applied Ergonomics Nottingham, UK, v. 13, n.2, p.107-117 1982.

SESTO, M. E., RADWIN, R. G., BEST, T. M.RICHARD, T. G. Upper limb mechanical changes following short duration repetitive eccentric exertions. Clinical Biomechanics (Bristol, Avon), Huddersfield, UK, v.19, n.9, p.921-8. 2004.

SNOOK, S. H., CIRIELLO, V. M.WEBSTER, B. S. Maximum acceptable forces for repetitive wrist extension with a pinch grip. International Journal of Industrial Ergonomics, Clemson, v.24, p.579-590. 1999.

STEVENSON, M. G., COLEMAN, N., LONG, A. F.WILLIAMSON, A. M. Assessment, re-design and evaluation of changes to the driver's cab in a suburban electric train. Appl Ergon, Nottingham, UK, v.31, n.5, p.499-506. 2000.

TAUBE, O. L. S. ANÁLISE DA INCIDÊNCIA DE DISTÚRBIOS MUSCULOESQUELÉTICOS NO TRABALHO DO BIBLIOTECÁRIO. CONSIDERAÇÕES ERGONÔMICAS COM ENFOQUE PREVENTIVO DE LER/DORT. 2002. f. (DISSERTAÇÃO DE MESTRADO). Departamento de Engenharia de Produção e Sistemas, UFSC, Florianópolis.

WISNER, A. Por dentro do trabalho : ergonomia, método e técnica. Saõ Paulo: FTD. 1987 
YENG, L. T., TEIXEIRA, M. J., ROMANO, M. A., PICARELLI, H., SETTIMI, M. M.GERVE, J. M. D. A. Distúrbios ósteo-musculares relacionados ao trabalho. Revista de Medicina, São Paulo, v.Edição Especial, p.422-442. 2001.

ZANDOMENEGHI, A. L. A. D. O. ORGANIZAÇÃO HUMANISTA - A ORGANIZAÇÃO QUE QUALIFICA AS RELAÇÕES DAS PESSOAS COM O TRABALHO Um estudo de caso. 1999. f. (DISSERTAÇÃO DE MESTRADO). UFSC, Florianópolis. 


\section{ANEXOS}

ANEXO I

Valores das medidas antropométricas para o peso corporal, envergadura, comprimento do braço, antebraço e mão.

\begin{tabular}{cccccc}
\hline Maquinista & Peso $(\mathbf{k g})$ & Env $(\mathbf{c m})$ & Braço $(\mathbf{c m})$ & Antebraço $(\mathbf{c m})$ & Mão $(\mathbf{c m})$ \\
\hline M1 & 90 & 182 & 36 & 27 & 10 \\
M2 & 80 & 180,5 & 37 & 24 & 9 \\
M3 & 72 & 192 & 39 & 28,5 & 9 \\
M4 & 74 & 165 & 31 & 23,5 & 9 \\
M5 & 75 & 173 & 33 & 25 & 10 \\
M6 & 71 & 180 & 33 & 27 & 10,5 \\
M7 & 85 & 164 & 31,5 & 25,5 & 8,5 \\
M8 & 95 & 186 & 38 & 28,5 & 10 \\
M9 & 70 & 172 & 33,5 & 27 & 9,5 \\
M10 & 86 & 189 & 36,5 & 27 & 10 \\
\hline Média & 79,8 & 178,4 & 34,9 & 26,3 & 9,6 \\
Desvio & 8,8 & 9,6 & 2,8 & 1,7 & 0,6 \\
\hline
\end{tabular}

ANEXO II

\section{Anamnese}


CÓD IDENTIFICAÇÃO:

1. HÁ QUANTO TEMPO EXERCE A FUNÇÃO DE OPERADOR DE TREM? ANOS E MESES

2. QUANTO TEMPO, DURANTE A JORNADA DE TRABALHO, PERMANECE EFETIVAMENTE OPERANDO? HORAS E MINUTOS

3. DURANTE A TAREFA DE OPERAR A MANETE DE TRAÇÃO, UTILIZA OUTRA POSTURA QUE NÃO SEJA COM O MEMBRO SUPERIOR ESQUEDO?

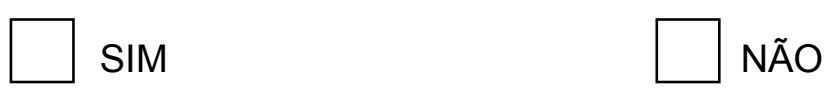

SE SIM, QUANTAS VEZES DURANTE A JORNADA DE TRABALHO? VEZES

4. QUAL SUA DOMINÂNCIA LATERAL PARA MEMBROS SUPERIORES?

$\square$ DIREITA

$\square$ ESQUERDA

5. JÁ SOFREU ALGUM TRAUMA OU ENFERMIDADE NO MEMBRO SUPERIOR ESQUERDO?

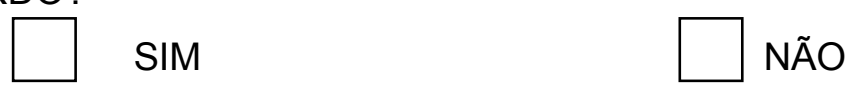

QUAL?

6. REALIZA ALGUMA PRÁTICA DESPORTIVA, DE RECREAÇÃO OU LAZER, DENTRE AS CITADAS ABAIXO?

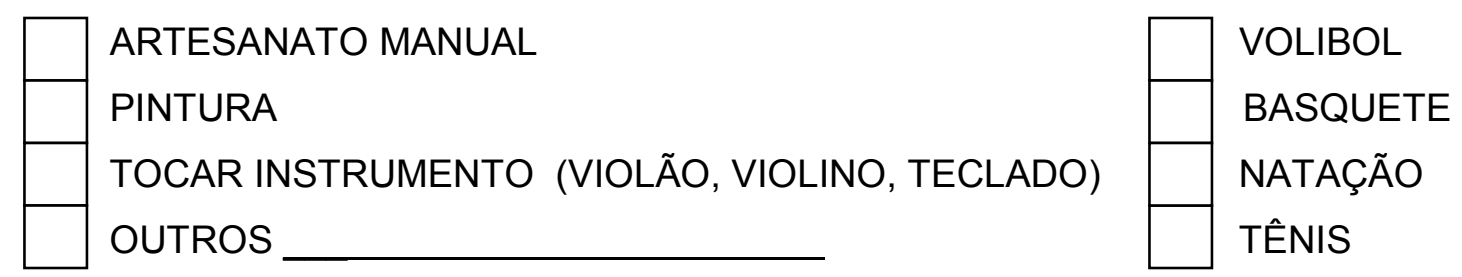


7. EM RELAÇÃO AO MEMBRO SUPERIOR ESQUERDO, VOCÊ TEM ALGUMA QUEIXA, OU INCOMODO?

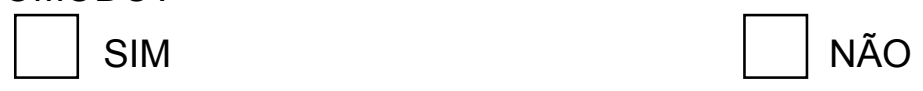

8. QUAIS OS SINTOMAS RELATIVOS ÀS QUEIXAS ACIMA?

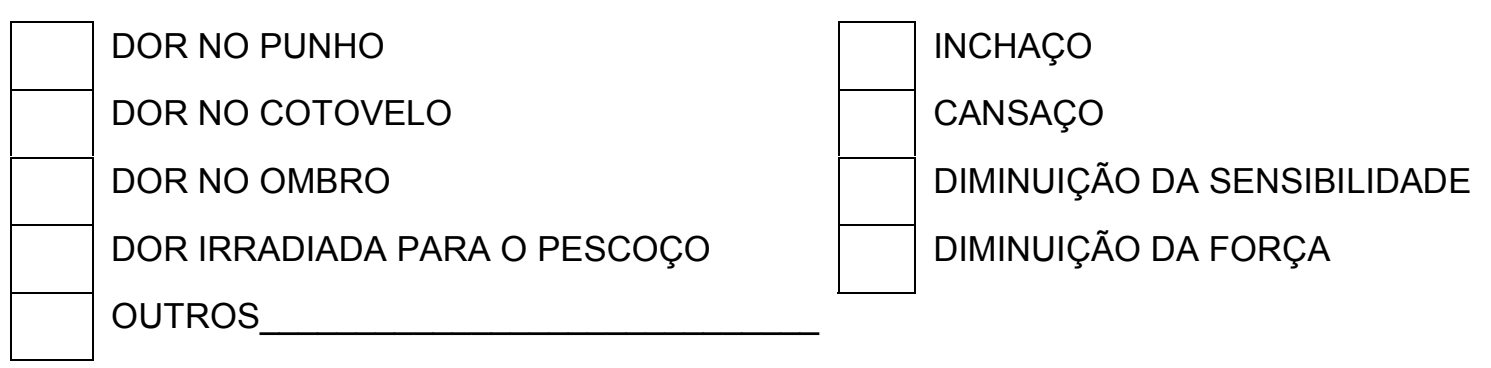

9. HÁ QUANTO TEMPO ESTES SINTOMAS APARECERAM? ANOS E MESES

10. QUANDO ESTES SINTOMAS APARECEM MAIS INTENSAMENTE?
$\square$ DURANTE O TRABALHO
$\square$ APÓS O TRABALHO
$\square$ DURANTE O DESCANÇO

ANEXO III 
Questionário Nórdico de Sintomas Osteomusculares - QNSO

Com base na figura humana ilustrada abaixo, você deverá registrar a frequeência em que tem sentido dor. dormência, formigamento ou desconforto nas regiões numeradas do desenho do corpo.

Suas opções de resposta são as exibidas na escala a seguir:
(0) Não
(1) Raramente
(2) Com freqüência
(3) Sempre

\section{Exemplo:}

Considerando os últimos 12 meses, você tem tido algum problema (tal como dor, desconforto ou dormência) nas seguintes regióes:

Se você tem sentido dores no pescoço com freqüència, vocé deverá assinalar o número 2

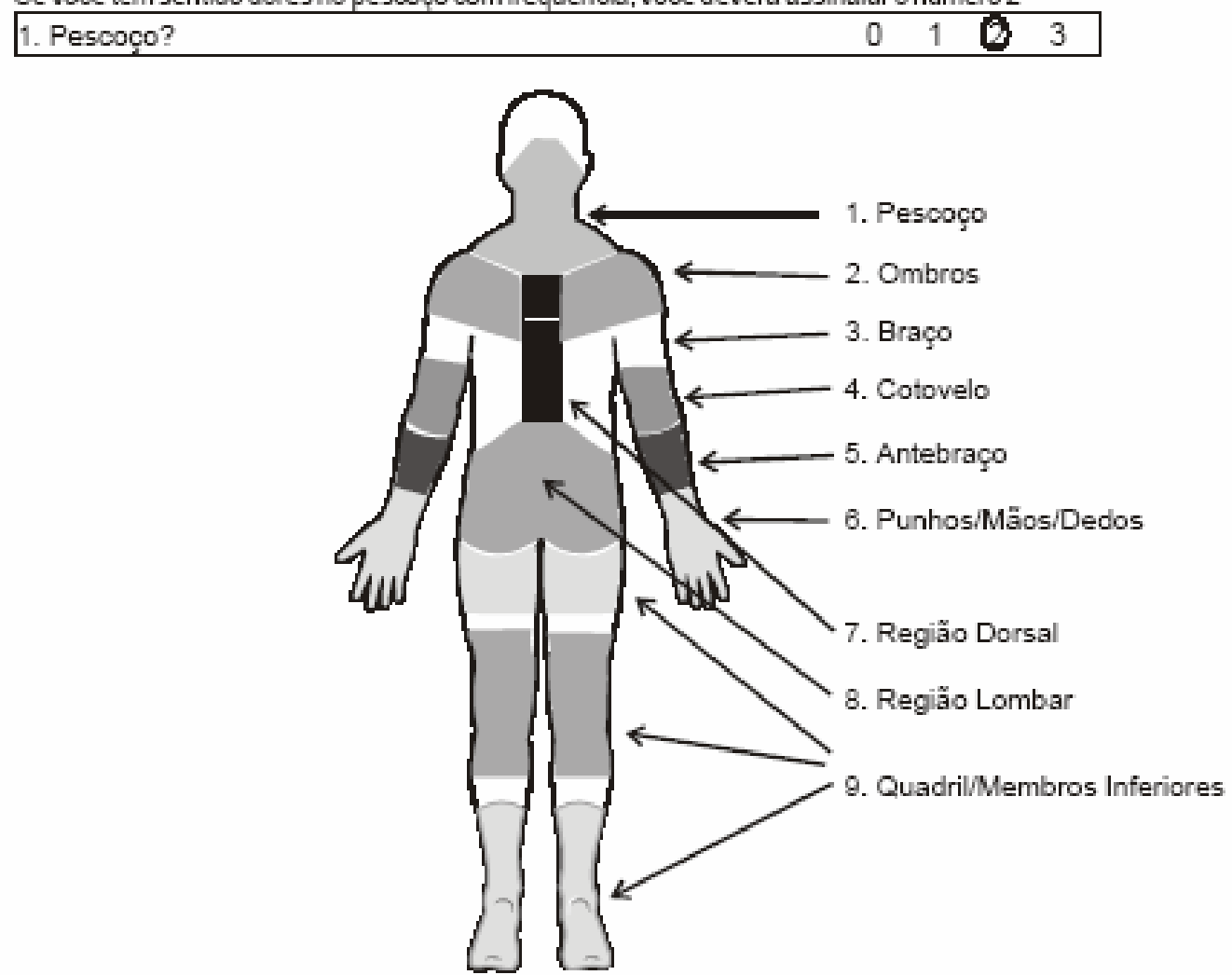

Considerando os últimos 12 meses, você tem tido algum problema (tal como dor, desconforto ou dormência) nas seguintes regiões:

\begin{tabular}{|l|llll|}
\hline 1. Pescoç/Regiäo cervical? & 0 & 1 & 2 & 3 \\
\hline 2. Ombros? & 0 & 1 & 2 & 3 \\
\hline 3. Braços? & 0 & 1 & 2 & 3 \\
\hline 4. Cotovelos? & 0 & 1 & 2 & 3 \\
\hline 5. Antebraços? & 0 & 1 & 2 & 3 \\
\hline 6. Punhos/Mãos/Dedos? & 0 & 1 & 2 & 3 \\
\hline 7. Região dorsal? & 0 & 1 & 2 & 3 \\
\hline 8. Região lombar? & 0 & 1 & 2 & 3 \\
\hline 9.Quadril/ Membros inferiores? & 0 & 1 & 2 & 3 \\
\hline
\end{tabular}


Considerando suas respostas ao quadro anterior, em que caso(s) você acha que os sintomas estão relacionados ao trabalho que realiza? (é possível assinalar mais que um item)
1. $\square$ Nenhum deles
2. $\square$ Problemas no pescoço/região cervical
3. Problemas nos ombros
4. $\square$ Problemas nos braços
5. $\square$ Problemas nos cotovelos

6. $\square$ Problemas nos antebraços

7. Problemas nos punhos/mäos/dedos

8. $\square$ Problemas na região dorsal

9. $\square$ Problemas na região lombar

$10 \square$ Problemas no quadril/membros inferiores

\section{Dados Demográficos (não coloque seu nome)}

Data do preenchimento

1. Sexo:

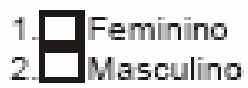

2. Estado Civil: 1. $\square$ Casado/vive maritalmente 2. $\square$ Solteiro

3. Idade: anos

4. Escolaridade:

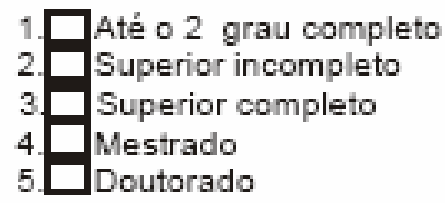

\section{Especialidade(s):}

6. Há quantos anos você exerce a mesma atividade?

7. Há quantos anos trabalha como operador

8. Em média, você trabalha por dia:

1
2
2
3

9. Você fuma, ou fumava a um ano atrás? 1. $\square$ Sim

10. Você é:

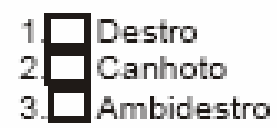

11. Você tem outra atividade profissional?

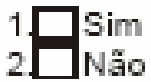

Qual?
12. Você exerce algum tipo de atividade física, regularmente? (Três ou mais vezes por semana, com no mínimo 30 minutos de duração)

2. ${ }_{\text {S }}^{\text {Sim }}$

Qual?

13. A seguir, assinale a(s) alternativa(s) que representam atividade que faz (em) parte do seu dia-a-dia (é possivel assinalar mais que uma alternativa):

1. $\square$ Executar atividades domésticas como lavar ou passar roupa, limpar a casa, lavar louça, etc

2. Tocar instrumento musical

3. Realizar trabalhos manuais (como tricô, crochê, escrita freqūente, etc)

4. Usar o microcomputador fora do trabalho

5. Praticar tênis, squash, outra atividade física com grande utilização dos membros superiores

6 Cuidar de crianças em idade pré-escolar

7 Nenhuma das anteriores

14. Assinale, dentre as alternativas abaixo, aquela(s) que corresponda(m) a diagnóstico(s) que vocé tenha recebido de algum médico, nos últimos 12 meses:

1. $\square$ Hipotireoidismo

2. Artrite

3. Diabetes

4. Fibromialgia

5. Hérnia de disco

6. Cäibra do escrivão

$7 . \square$ Gota

8. $\square$ LER/DORT

9. $\square$ Fraturas ou lesöes acidentais: indique a área afetada

10. $\square$ Nenhuma das anteriores

Obrigado por sua valiosa colaboração. A Equipe de Pesquisa 